


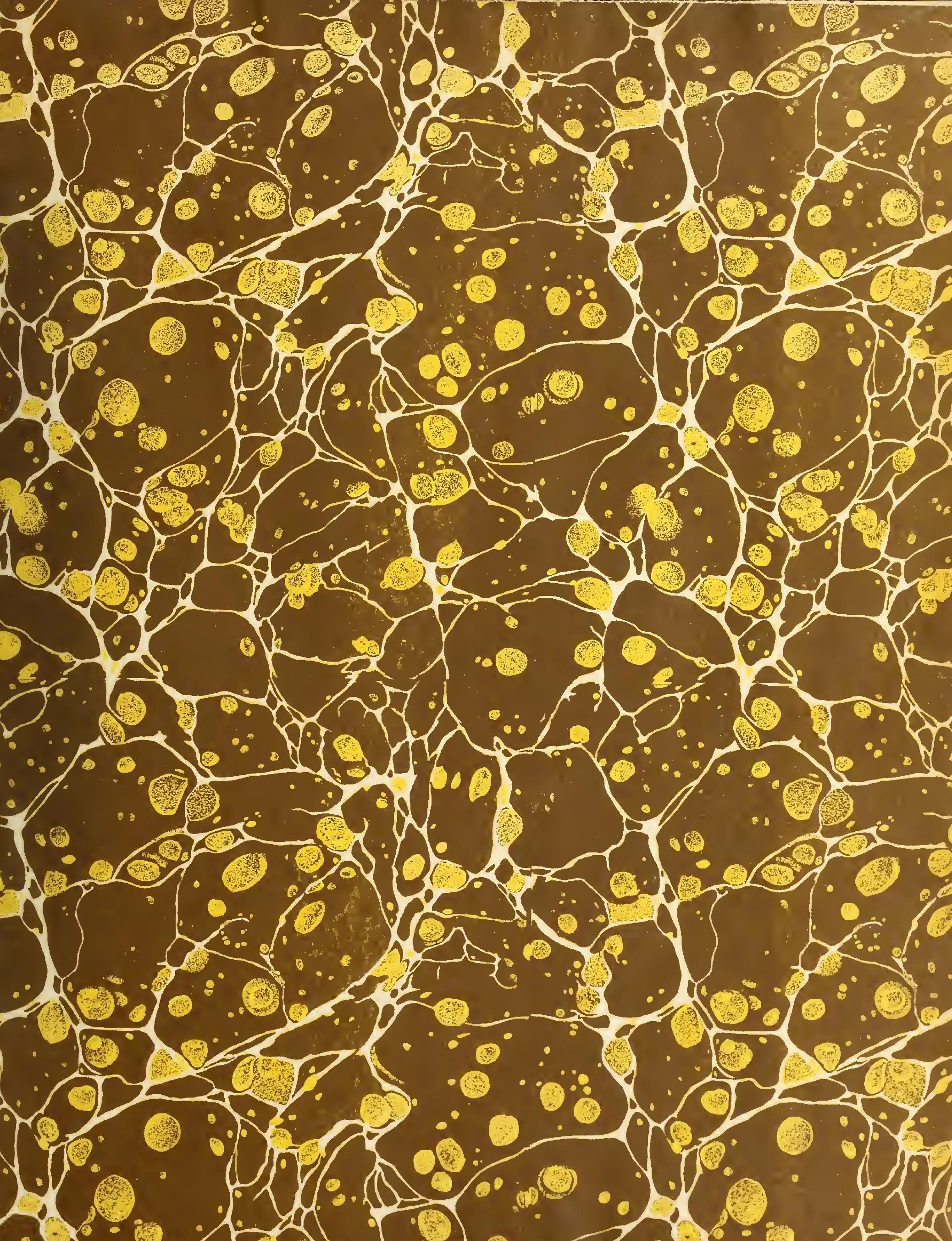






Bubva os statares

FEB 111932

40149

HIIG

12

sep. 6 


\section{COMMERCIAL}

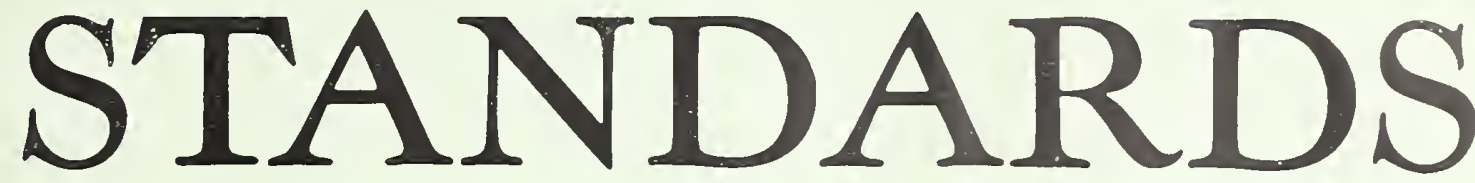

UREAU OF SEAWUAS
JUL 2 E 1930

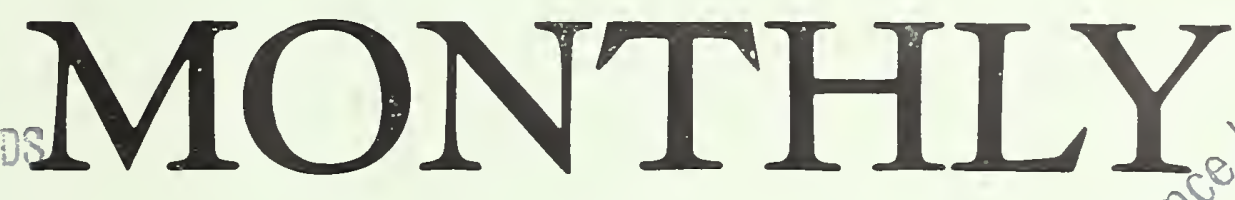

T

LIBRARY

A Review of Progress in

Commercial Standardization and Simplification

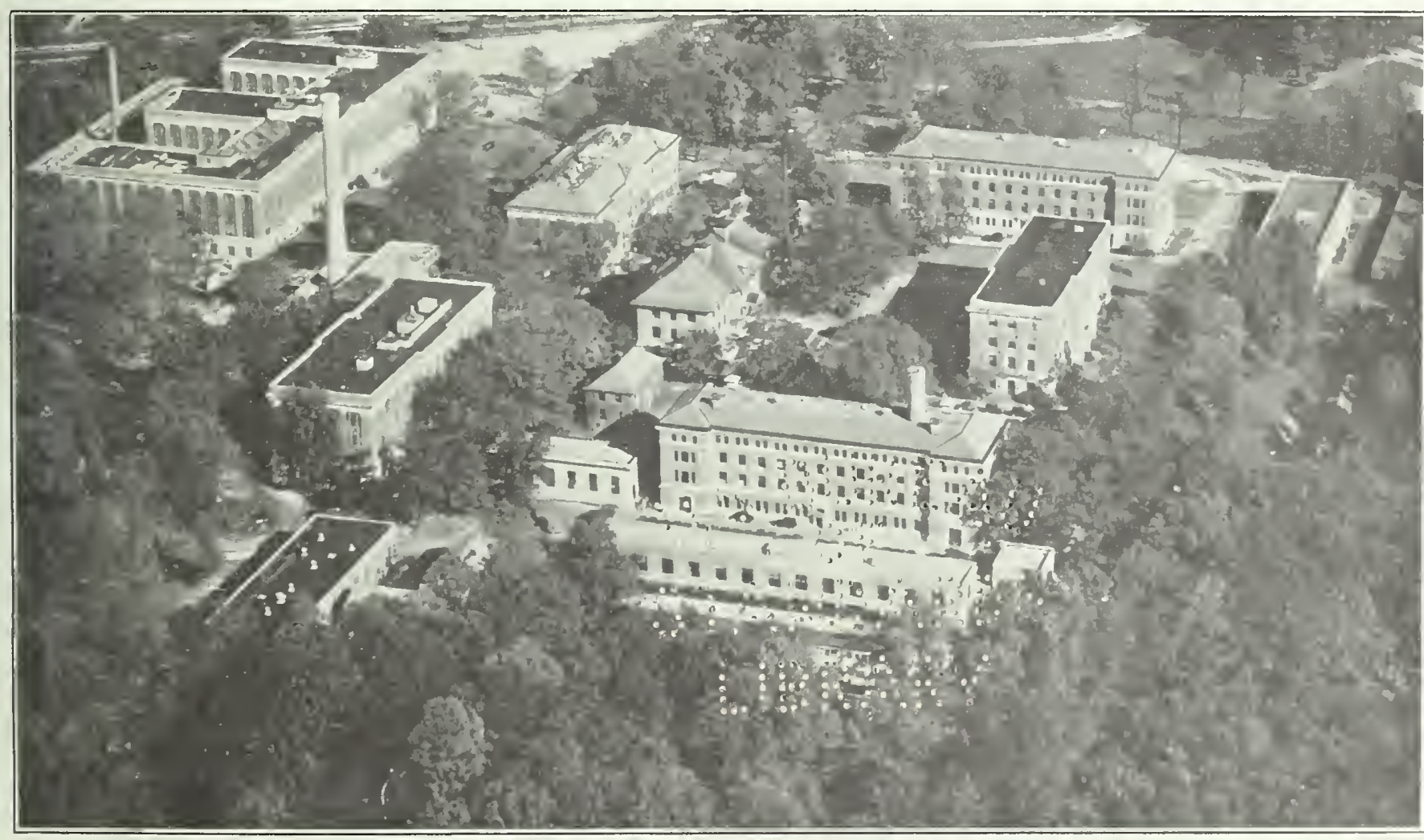

AIRPLANE VIEW OF NATIONAL BUREAU OF STANDARDS

ISSUED BY THE NATIONAL BUREAU OF STANDARDS OF THE UNITED STATES DEPARTMENT OF COMMERCE, WASHINGTON, D.C., U.S.A.

Vol. 7, No. 1

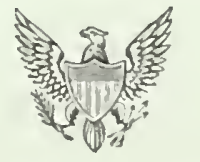

JULY, 1930 


\section{U. S. DEPARTMENT OF COMMERCE \\ R. P. LAMONT, Secretary}

NATIONAL BUREAU OF STANDARDS

George K. Burgess, Director

COMMERCIAL STANDARDS MONTHLY

S. F. Tillman, Editor

\section{DIVISIONS OF THE COMMERCIAL STANDARDIZATION GROUP}

DIVISION OF SIMPLIFIED PRACTICE, Edwin W. Ely.

'The division of simplified practice was formed in November, 1921 , to provide a clearing house or centralizing agency througl which the manufacturer, distributor, and consumer groups could meet to discuss their common problems and decide upon eliminations which would prove of mutual benefit to all concerned. The activities of the division are purely cooperative in character. It orders nothing; it dictates nothing; the initiative must come from business itself. It has no regulatory nor police powers to enforce adherence to the simplified-practice recommendations that industry develops under the auspices of the United States Department of Commerce. Its chief function is to serve as a neutral meeting ground for the purpose of bringing together producers, distributors, and consumers, whose aims are sometimes divergent and possibly antagonistic, and who would be unwilling to cooperate, except through some unbiased central agency. Following the approval of the tentative simplified-practice recommendation by a general conference of all interested elements thereof, the project is then presented to the entire industry by letter referendim for its approval and written acceptance, the publication and indorsement of the recommendation on the part of the Department of Commerce being dependent upon acceptance of the program by at least 80 per cent, by volume, of the manufacturers, distributors, and users concerned.

\section{BUILDING AND HOUSING DIVISJON, J. S. TAYLOR,}

The division of building and housing cooperates with business, technical, and professional groups in practically all its undertakings on building and housing. Its work to modernize building codes and to encourage improved.stamedro for the quality of building construction promotes ape plication of the latest development.ir. design ând use of ing materials. This division was äso formed in: $192 \%$.

In furthering home ownership, an effort is made $10^{\circ}$ develop

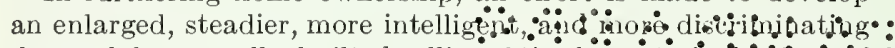

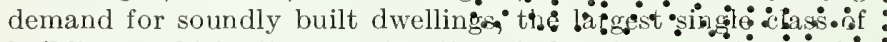
buildings which the construction industries provide. "The division also cooperates with many busin as a groups in efforts to distribute building:acpigity throughout the year, and to secure less fluctuation from yeär to year. The work on eity planning and zoning has in mind the broad objective of buildings made more useful because well located with respect to other buildings, a well-coordinated street system, and appropriate public works. Good city planning and zoning likewise encourages stability in land values and property uses, and thereby contributes to the dcmand for durable structures.
DIVISION OF SPECIFICATIONS, A. S. MCALLISTER.

The duties of the division of specifications are to promote and facilitate the use and unification of specifications. In doing so it carries on activities involving cooperation with technical societies; trade associations; Federal, State, and municipal Government specifications making and using agencies; producers, distributors, and consumers; and testing and reseurch laboratories. The cooperation with technical societies and trade associations includes ascertaining the standardization and specification promoting activities of these organizations, and bringing to their attention the work being done by the commercial standardization group. The cooperation with governmental agencies and other consumers includes the bringing of Federal specifications and commercial standards to the attention of the maximum number of producers and the maximum number of users of commodities complying with these specifications and stalldards, thereby assisting in broadening the field of supply. The cooperation with producers involves the compilation and distribution of lists of manufacturers who have expressed their willingness to certify to purchasers, upon request, that material supplied by them on contracts based on certain Federal specifications or commercial standards comply with the requirements thereof. The cooperation with distributors involves bringing to their attention the benefits to be derived by them as both buyers and sellers from handling national!y specified, certified, and labeled commodities. The division prepares the directories of governmental and nongovernmental testing laboratories; the Directory of Specifications; and is working on an encyclopedia of specifications, the first volume of which, Standards and Specifications in the WoodUsing Industries, has been issued. It also aids in preparing the Standards Yearbrok.

DIVISION OF TRADE STANDARDS, I. J. FAlRChILd.

$\therefore$ The commercial standards unit, now known as division of - trade standards, was created on October 1, 1927, for the purpose of aiding those industrial and commercial groups desiring to establish standards of grades, quality, or measurements for their products or their purchases on a purely voluntary basis.

- The division functions only at the direct request of the industry concerned. Its procedure is similar to that of the division of simplified practice, except that at least 65 per cent of the industry, by volume of annual production, must accept the commercial standard in writing before it is published by the Department of Commerce. A certification plan is applied on request as a means of incressing the effectiveness of such standards. Provision is made for regnlar revision of the standard through the appointment of a standing committee to consider periodically any necessity for revision of the standard, in order that it may be kept constantly compatible with progress in the industry.

Except where otherwise indicated, for further information address BUREAU OF STANDARDS

WASHINGTON, D. C. 


\title{
COMMERCIAL STANDARDS MONTHLY
}

\author{
A Review of Progress in \\ Commercial Standardization and Simplification
}

\section{CONTEN'TS}

\section{FEATURE ARTICLES}

Accidents in the home

Cooperation in reducing industrial aceidents.

Discrimination in purehasing

Gasoline and steam engines improved through research

National weights and measures conference ...........

Reducing accidents among automobile drivers -

Some random suggestions on the purchase of paints

Standard specifications for road equipment

Standardizing Army equipment

Standardization - should it be feared or fostered?.....

Standards of service in the electrical industry

Testing typewriter ribbons

Uniformity of traffic laws urged

Value of listribution census to manfacturer

\section{SIMPLIFIED PRACTICE ITEMS}

Industry to study stock sizes for polished cotton twine. -

\section{STANDARDIZATION ITEMS}

Current activities of the American Standards Association. Maximum spans for joists and rafters _............. Revision of Federal specifications Standardization briefs

\begin{tabular}{r|} 
Page \\
16 \\
17 \\
18 \\
8 \\
9 \\
11 \\
3 \\
24 \\
14 \\
20 \\
22 \\
26 \\
28 \\
30 \\
\\
\\
21 \\
\\
31 \\
29 \\
7 \\
27
\end{tabular}

TRADE STANDARD ITEMS

American National special serew threads _._._._._... 25

Feldspar standard adopted by industry

Hickory golf shafts

Plug and ring gage blanks

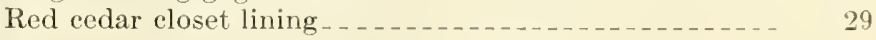

\section{RESEARCH ITEMS}

Composite beams and slabs of hollow tile and concrete

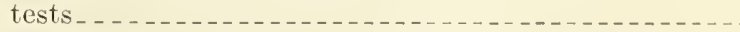

New standard of light first suggested by Waidner and Burgess_._._._. 30

Performance characteristies of 2-blade propeller fans_- 23 Platinum plating for analytical weights

Research on purified wood fibers _................ 21

Specification for roofing slate_._._._.

\section{FOREIGN ITEMS}

British specification for vandyke brown

$\mathrm{Br}$ itish standard covers aluminum conductors

\section{AN INVITATION TO VISIT THE BUREAU OF STANDARDS}

An interesting fact in the growth of the bureau is the, steady increase in the number of visitors. From all over the world experts come to see the work' in progress' in many specialties. Not alone the experts but in growing numbers many of our people visite the bureaư 'from a public-spirited desire to aequaint themselves with its researeh work. All visiors, from thewspapermen, who have ealled the bureau a "house of wonders," to the specialists, who use its services, are, welenme, for it is their bureau in a very real sense. They are the owners of the business and its benenciares. The annual per eapita cost of 2 cents which the average eitizen pays tow ${ }^{2}$ d the peration of "the bureau yields returns sometimes a hundredfold or a thousandfold. How seience turns, wastes into profits, inereases the useful lifo of materials, adds new effieieneies to industry, advanees' new' ars; such as aviation and radio, by researeh and discovery - these are to be seen first-hand in the soien'ticic and tuchnical laboratories of the bureau.

$A$ eordial invitation is extended to all eitizens interested in seientifie progress to visit the laboratories of the Bureau of Standards when in Washington. A personally condueted trip is organized at $2.15 \mathrm{p} . \mathrm{m}$. daily exeept on holidays. Speeial trips for groups may be arranged at other times by witing to the bureau in advanee. The bureau's illustrated Visitor's Manual may be had for the asking. 'This lists the work in progress and gives an airplane view of the ensemble and a brief statement of typieal diseoveries and inventions whieh have been notable, basic contributions to radio, aviation, and other modern arts and industries.

George K. Burgess, Director. 


\section{SAFETY STANDARDS on the HIGHWAY}

$\mathcal{T}_{R}$

RAFFIC ACCIDENTS in the United States have steadily increased year by year. In 1930 there were about 31,000 fatalities due to accidents in which motor vehicles were involved, or about 85 for each day in the year.

What can be done to improve this situation? To answer this question the Secretary of Commerce convened the Third National Conference on Street and Highway Safety, which is the subject of an article by Col. A. B. Barber in this issue of the Commercial Standards Monthly. The conference found this answer. Poor driving is undoubtedly responsible for a large number of accidents, and this element can probably be improved by a general requirement for the licensing of operators based upon the ability of the operator to demonstrate his fitness. This should be supplemented by prompt and systematic revocation of the licenses of those operators who have demonstrated their unfitness to drive.

But even for a good driver to avoid accidents it is desirable that he should be informed of conditions which he is approaching which might involve him in an accident. With the large amount of interurban and interstate traffic of the present day, this necessitates the intelligent use of signs and signals, which, to have the greatest usefulness, should be uniform in their character and uniformly applied. Furthermore, driving practices should be the same all over. regulations. $\because \because \because \because \because \because \because \because \because \because \because \because$

The conference made but few changes in the text of the uniform acts,

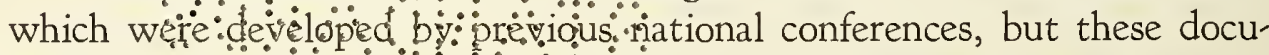
ments have been perfected in the light of wide experience in many parts of the country. There tion of the "uniform State acts," the "model municipal ordinance," and the standards for signs, signals, and pavement markings, especially as to those items which immediately affect the control of traffic on the public highways. Nearly all of the State legislatures will meet in 1931, and that year should be outstanding for the standardization of traffic regulations. 


\title{
SOME RANDOM SUGGESTIONS ON THE PURCHASE OF PAINTS
}

\author{
When and How Buyers Can Profitably Make Use of Approved Requirements
}

By Percy H. Walker, Chief, Paints and Varnish Section, National Bureau of Standards

The purchase of any kind of engineering material under definite specifications is a very modern development. So far as can be learned, the first serious effort along this line in America was made by Dr. C. B. Dudley, of the Pennsylvania Railroad System, and he entered the service of the Pennsylvania Railway System in November, 1875. That Dudley was the first man in America to attempt methods of test and specifications for other engineering materials may be open to question, but there is little doubt that he was the first one to seriously consider paint and paint materials. His first publications on this subject appeared about 1890 ; therefore, we may say that the whole development has taken place in the last 40 years.

Other large users, notably other railroads and the United States Navy, followed his lead, and ever since the latter part of the nineteenth century individual specifications for a variety of paint materials have been in use. There was, however, no pooling of interests by either producers or consumers, and anyone looking for a specification for any particular material would find such a wide difference in the requirements and in the methods of test that he would have great difficulty in deciding which specification to adopt and how to learn whether material delivered was in accordance with the specification.

In 1898 the American Section of the International Association for Testing Materials was organized, which in 1902 developed into the American Society for Testing Materials. The charter of this society states that it " is formed for the promotion of knowledge of the materials of engineering, and the standardization of specifications and the methods of test." The work of the A. S. T. M. is carried on by standing committees composed of producers, consumers, and representatives of general interest in the subjects handled by the particular committee. One of the oldest of such committees, first designated as Committee E, and later as Committee D-1, is concerned with paint and paint materials. From the time of its organization this committee has done invaluable service in developing and standardizing methods of test, thus laying an important part of the foundation of purchase specifications for paint and paint materials. Prior to the World War, however, it did not issue any specification covering the quality of a paint material.

War interest in purchasing.

When the United States entered the World War, the Government needed immense quantities of paint and paint materials, and it had no standard specifications, the specifications for a given material intended for the same use being different in the various branches of the service. The paint committee of the War Industries Board realized the necessity of standardizing the Government specifications, and this committee was making such satisfactory progress when the war ended that it requested the Secretary of Commerce to continue this work.
As a result of a request from this committee, which represented the American paint industry, there was organized in February, 1919, an interdepartmental committee on paint specifications standardization which, in cooperation with manufacturers, prepared a number of specifications which were recommended for use by all Government agencies. These specifications were recommended. The interdepartmental committee had no authority, and did not seek authority, to force the adoption of its specifications by any branch of the service. However, I believe they were generally used by the various Government agencies.

In October, 1921, the Bureau of the Budget organized the Federal Specifications Board "to compile and adopt standard specifications for materials and services and to bring the Government specifications into harmony with the best commercial practice wherever conditions permitted, bearing in mind the desirability of broadening the field of supply." The old interdepartmental committee on paint specification standardization was appointed by the Federal Specifications Board as its technical committee on paints and oil, and its recommended specifications were promulgated by the board as standard specifications to be used by the various branches of the service.

\section{Method of procedure.}

Since this was the first attempt of a very large group of consumers to prepare specifications for paint and paint materials with extensive cooperation with the manufacturers, it may be of interest to review the method followed. The use of specifications must involve sampling and testing of deliveries, and since there may be misunderstanding as to how a specific material should be tested it was decided to incorporate in each specification, in addition to the description of the material wanted, detailed directions for sampling and testing. "In iothen words, we aimed to have tlie technicaí rềuirements so explicit as to eliminate any possibility of dispute.

A proposed draft of the specification, giving methods of sanpiting and tescing, was prepared by the commitite and submitted to all interested manufacturers with a request for: constructive criticism and suggesticns 'a's' $t_{1}$ " improvements. All such comments were then carefully corsidered, and the specification rewritten if the comments showed that rewriting would improve it. It was then submitted to the various departments for final criticism and possible cor'rection before adoption. The specification was finally adoptec by the board on recommendation from the technical committee after considering all comments.

\section{Specification needed to cover requirements.}

It was made perfectly plain to Committee D-1 of the A. S. T. M. that the Government had no desire to have any exclusive authorship of paint specifications, but wished to adopt any existing specifications that would meet its needs. If the A. S. T. M. had prepared such specifications we would certainly have adopted 
them. Many of the men most interested in the Govermment specifications are also members of Committee $\mathrm{D}-1$, and this committee has in the last few years adopted a number of the F. S. B. specifications; it has formulated others which will undoubtedly be adopted by the Federal Specifications Board. In fact, except for delay due to a change in form and method of publication by the F. S. B., most of the A. S. T. M. specifications would now be also F. S. B. specifications.

The cordial cooperation of the A. S. T. M. committee and the Federal committee makes it almost certain that neither committee will adopt any specification that is radically different from a specification for the same kind of material adopted by the other committee. This does not mean that each committee will necessarily adopt all of the specifications adopted by the other.

Lnoking over the titles and numbers of the A. S. T. M. standard and tentative specifications, we find 25 covering materials for structural paincing, and 1 more will probably be adopted in June. A corresponding survey of the F. S. B. list shows 29 adopted specifications, and 7 more will be adopted in the near future. In Table 1 there is given a summary showing that, eliminating duplications, there are 41 available specifications that can be relied upon as having been carefully prepared and representing the best judgment, at the time of preparation, of the committees preparing them. The explanation may serve to indicate some important things in the specification that a user must bear in mind. This table is merely a rough guide. It can not be taken as a substitute for reading and understanding each specification that is to be used.

\section{Two methods of procuring paints.}

Attention is called to the fact that there are two methods of procuring paint ready for use. The older method is to mix the paint for each job; that is, the painter secures certain raw or partially prepared materials and mixes them to make the desired paint. The other method is to buy the paint ready for application. It will be noted that the $\mathbf{\Lambda}$. S. T. M. specifications cover a wide variety of materials for mixing on the job, but no mixed paints. $\because$ The

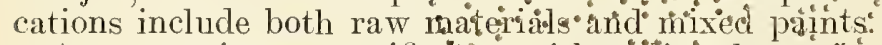

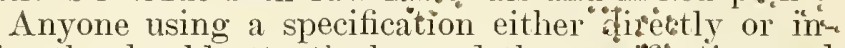
directly should attentively read the specification and

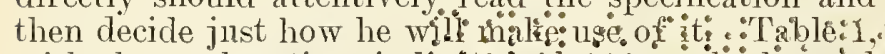

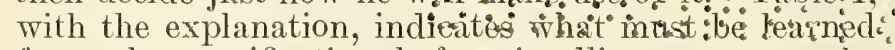
from the specification before. intelligent use can be

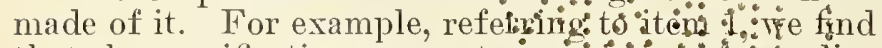

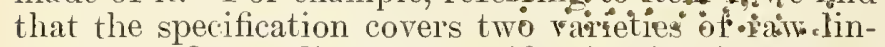
seed oil. On reading the specification it will be seen that one has a minimum iodine number of 177 and the other 188. The buyer should decide which he wants, and if he buys under the specification should select the variety he desires and so state in his invitation for bids. He then needs nothing else except to assure himself that the delivery meets the specification. He not only needs no precontract sample, but it is unwise to accept such a sample.

A similar reference to item 8 and the corresponding specification will show that the white lead may be procured either as dry pigment or paste, and the buyer must state which he wants. He will also find that when color or color strength are specified the deliver'y must be equal in these respects to a sample mutually agreed upon by buyer and seller. Since different lots of white lead do not vary greatly in these respects, it is not generally necessary to agree upon a sample. If, however, the material is to be used for making some delicate tints, it may be necessary to agree upon a sample with which to compare deliveries for color and color strength only.

\section{Variety in chrome yellow.}

Referring to item 15 and the corresponding specification, we find that chrome yellow can be furnished either as dry pigment, paste in oil, or paste in japan. The buyer must state which form he wants. He will also find that a great variety of colors can properly be called chrome yellow. The selection of the one desired is entirely a matter of taste. There is no practical method of getting the color desired, except that of having it match in color, character of tint, and tinting strength a sample mutually agreed upon.

Referring to items $26,27,28,29,30$, and 39 it will be seen that these paints are obtainable as semipaste and as ready-mixed paint. In my opinion the semipaste is the preferred form. My reasons for this are (1) that there is generally less labor involved in mixing a semipaste with the necessary oil, drier, and thinner than in properly mixing the more or less settled pigment in a container of ready-mixed paint with the liquid floating on top, (2) there seems to be a universal tendency for every painter to add something to any paint given to him, and the semipaste, having the desired color and containing considerable oil, can be properly diluted and is generally less likely to be ruined by improper dilution than is a ready-mixed paint. In other words, the semipaste seems to be the most nearly foolproof.

While I believe that the list of 41 items in Table 1 is the best available list of specifications, I do not consider all of them the best that can be prepared. For example, attention is invited to item 29, which refers to U. S. Government Master Specification for White Paint and Tinted Paints Made on a White Base, Semipaste and Ready-Mixed, B. S. Circular No. 89.

When the committee adopted this specification we thought we had a good title and a good specification that would insure a wide source of supply, but the subsequent appearance of excellent white paints conitaining more than 15 per cent of titanium pigments "has shown that the term "white base" instead of "lead-zinc" in the title was a mistake. Of greater importance, however, is the joker in the pigment specification. This specification states that the pigment shall be composed of-

\begin{tabular}{|c|c|c|}
\hline & $\begin{array}{l}\text { Maxi- } \\
\text { mum }\end{array}$ & $\begin{array}{l}\text { Mini- } \\
\text { mum }\end{array}$ \\
\hline & Per cent & Per cent \\
\hline $\begin{array}{l}\text { White lead (basic carbonate, basic sulphate, or a mixture thereof) } \\
\text { Zinc oxide }\end{array}$ & $\begin{array}{l}70 \\
55\end{array}$ & $\begin{array}{l}45 \\
30\end{array}$ \\
\hline $\begin{array}{l}\text { White mineral pigments, containing no lead or zinc compounds, } \\
\text { pure tinting colors, or any mixture thereof }\end{array}$ & 15 & 0 \\
\hline
\end{tabular}

A careful reading of this pigment specification shows that a great variety of mixtures equally fill the requirement. If the reader will compare the formulas 
of most of the high-grade learl-zinc paints on the market, he will find that almost all of them fall within the limits of the specification. One who does not consider the cost of the components will come to the erroneous conclusion that they can be bought in competition under the specification. Experience in Ferleral purchases has clearly shown that this is not the case.

Any manufacturer has a right to assume that any composition falling within the limits of the specification is acceptable, and he will naturally furnish the one that will cost him the least. The most expensive component of this pigment is white lead, and the least expensive is the white mineral pigments containing no lead or zinc compounds. The bidder will, therefore, figure on a pigment containing 15 per cent of an extender, such as asbestine, the equivalent of 45 per cent of white lead, and the remainder (40 per cent) of zine oxide.

This is approximately what will always be clelivered, and it does not give as good a paint as one containing more lead and less extender' and zinc. The Government committee is now considering a revision of this specification. The revision may prescribe sereral grades, each with definite minimum limits of lead and a maximum limit of extenders, the remainder in all cases to be zinc oxide. From the way the present specification is written and made obligatory for Gorernment purchases, such revision is necessary for Government use before the specification can be considered satisfactory. For users who are privileged to make modifications of the present specification it is recommended raising the ininimum of white lead to $60 \mathrm{per}$ cent. If no other changes are made in the specification, except increasing the ninimum white-lead content, a minimum limit of 60 per cent white lead will give a pigment containing 10 per cent extender, 30 per cent zinc oxide, and 60 per cent white lead. A minimum of 70 per cent white lead will give a pioment of 70 per cent white lead and 30 per cent of zinc oxide.

It will be noted that in the other specifications that cover ready-mixed paint (items $26,27,28,30,31,38$, 39 , and 40 ) there is no ambiguity as to the meaning of the pigment composition; that is, in each case defiuite maximum or minimum limits are prescribed.

\section{Advantages of specifications.}

How can a purchasing agent make adrantageous use of specifications? No single answer can be given to such a question; but first let's point out what are believed to be the adrantages and the disadrantages of purchasing under specifications and then see what use a purchasing oflicer with porrer to use his best judgment an make of specifications. Briefly, the adrantages of a properly drawn sperification is that it cloarly states just what the minmum requirements are for the material in question, so that all bidders can bid on the same quality and kind of material. It furnishes the buyer directions for testing. so that any man with adequate knowledge and equipment can learn from the cxamination of the delivered material whether it does or does not meet the requirements.

The disadvantages of a specification are that it does lsot make any distinction between material jüst passing and material of distinctly higher quality, and that it places the responsibility of finding out that the material does or does not comply, on the purchaser. If material is in compliance with the specification and is nevertheless not satisfactory, the buryer and not the seller must stand the loss. Inspection and testing cost money, and the cost of such inspection and testing should properly be added to the purchase price in comparing cost of material bought strictly under specification with similar material bought on the reputation of the seller without tests. Considering the use a purchasing agent can make of specifications, let us assume three cases.

We will assume that the buyer has or can get the service of competent inspectors and testing laboratories and that he frequently buys large lots of the same kind of material, each item in every order amounting to several hundred dollars. It will pay this buyer to use a specification and buy from the lowest responsible bidder. He should see that the inspector reads and understands the specification and that at the time of inspecting he makes the simple tests that are as important as the more complicated laboratory tests. If the inspector convinces himself that the material does not comply with these easily determined requirements, he should reject the material without incurring the expense of laboratory tests. In other words, no samples should be sent to the laboratory for test except such as have passed all tests that the inspector can make at the time of drawing the sample.

The inspector should be required to assume the responsibility of intelligent inspection and should not be permitted to transmit obviously unsatisfactory material to the laboratory. When, and only when, the inspector thinks the material is satisfactory should he send a sample for the more expensive laboratory tests. No delivery should be accepted until a properly taken sample has been tested and found to comply with the specification.

We will assume that the buyer occasionally needs small amounts of paint material, no single order inrolving any great cost. Under these circumstances, if possible, let the man who will use the material consult a reliable dealer and buy what the user and the dealer recommend as probably satisfactory. It is hard to think of a more foolish procedure than the strict use of specifications for such small purchases.

\section{Buying at frequent intervals.}

TVe will assume that the buyer must purchase moderately large lots at rather frequent intervals for use by different branches of his organization. but not enough to regularly employ inspectors and testing laboratories. He has recommended to him a number" of different manufacturers' products at raryin prices. the salesman of each claiming that his material is better than the others. 'The buyer can then select a specification and in any available manner ascertain which of the materials offered meet the specification. Tre can eliminate from consideration the products that do not comply with the selected specification and select from the renaining the products made by manufacturers known to be entirely trustworthy. In this way he can get reasonable competition, as well as force salesmon to cliscuss facts rather than extravagant claims. 
The user of any extensively advertised product pays for a good deal of printer's ink. It is the consumer who pays for all sales cost, including full-page advertisements in the popular magazines. The man who buys strictly according to specifications will often be told by salesmen that the material he is getting can not be made at the price paid. This statement is sometimes true, a contractor may lose on a contract or he may be dishonest and expect to "beat" the specification, but in many cases the rival salesman does not know what he is talking about, because he adds the cost of selling the name to the cost of the material without considering that the man buying under a specification is buying material and not a name.

While it will take technical knowledge to accurately compute the cost of any given paint or varnish material, there are three raw materials which may be safely used as rough indications of what should be maximum prices. These are white lead, red lead, and linseed oil. No oil varnish, or thinning liquid, will cost the manufacturer any more than linseed oil-such products can generally be made for considerably less than the cost of linseed oil. The most costly house paint is a straight white-lead paint. Such a paint will weigh about $191 / 3$ pounds to a gallon and will contain about 70 per cent of pigment. Hence, the cost of a gallon of house paint should never be more than, and should generally be considerably less than the cost of $131 / 2$ pounds of white lead $+53 / 4$ pounds ( $3 / 4$ gallon) of linseed oil.

Red-lead linseed-oil paint is the most costly paint used on steel. An ordinary recommended red-lead paint will have in a gallon 20 pounds of red lead and $53 / 4$ pounds ( $3 / 4$ gallon) of linseed oil. Most other paints for steel will cost considerably less than house paints.

To sum up, it is believed that no purchasing agent can better prepare himself for intelligent buying of paint than by a careful study of the specifications listed in Table 1. They will help the man who intelligently uses them, but they are not a substitute for common sense. If one wishes to keep their paint and painting costs down when buying under specifications or in any other way, use dark-colored paints whenever possible. Do not forget that white and light-tinted paints are not only the most expensive decorative structural paints, but are at the same time the least durable. Any white paint can be made distinctly more durable by tinting it.

On all surfaces except iron and steel, paint is used mainly for decoration, and the cost of keeping a structure painted will vary with the individual ideas as to what the decoration should be, with the kind of surface to be painted, and the location of that surface. The best paint for one surface may be worthless for another. Durability of the paint as well as retention of color and appearance is of great importance for outside work, but retention of color and appearance are the important considerations for an interior paint, because when properly applied on a surface that remains in good condition a paint that will last for only a few months outdoors will last for years in a room where no direct sunlight reaches it.

On the other hand, an oil-gloss white paint that will last well and remain white outdoors will turn yellow indoors. A mixture of pure water and pigment is about the poorest paint that can be imagined for application to exterior wood. Such a paint, if applied in a proper manner to freshly laid plaster, is the best paint that can be used on interior plaster.

TABLE 1.-Available specifications

\begin{tabular}{|c|c|c|c|c|c|}
\hline ltem & Material & $\begin{array}{l}\text { Vari- } \\
\text { eties }\end{array}$ & A. S. T. M. & F.S.B. & Remarks \\
\hline 1 & Raw linseed oil..... & 2 & D 234-28 & Yes... & (a), (c). \\
\hline 2 & Boiled linseed oil $\ldots \ldots \ldots$ & 2 & D $260-28$ & Yes... & (a), (c). \\
\hline 3 & $\begin{array}{l}\text { Petroleum spirits (mineral spir- } \\
\text { its). }\end{array}$ & 1 & D $235-26$ & Yes_-. & (a), (c). \\
\hline 4 & $\begin{array}{l}\text { Turpentine, gum spirits, steam. } \\
\text { distilled wood. }\end{array}$ & 2 & D $13-26$. & Yes... & (a), (d). \\
\hline 5 & $\begin{array}{l}\text { Turpentine, destructively dis- } \\
\text { tilled wood. }\end{array}$ & 1 & D $236-2$ & No_-.- & (a), (d). \\
\hline 6 & $\begin{array}{l}\text { Composite rehicle for thinning } \\
\text { semipaste paint when the use } \\
\text { of straight linseed oil is not } \\
\text { justified. }\end{array}$ & 1 & No.. & Yes.-- & (a), (c). \\
\hline $\begin{array}{l}7 \\
8\end{array}$ & Liquid paint drier & 2 & No_... & Yes... & (a), (c). \\
\hline 8 & $\begin{array}{l}\text { Basic carbonate white lead, dry } \\
\text { Basic carbonate white lead, } \\
\text { paste in oil. }\end{array}$ & $\begin{array}{l}1 \\
1\end{array}$ & $\begin{array}{l}\text { D } 81-2 \\
\text { D } 81-2\end{array}$ & $\begin{array}{l}\text { Yes.-. } \\
\text { Yes.-- }\end{array}$ & $\begin{array}{l}\text { (a), (d). } \\
\text { (a), (d). }\end{array}$ \\
\hline & $\begin{array}{l}\text { Basic carhonate white lead, soft } \\
\text { paste in oil. }\end{array}$ & 1 & No. & (1) & (a), (d). \\
\hline & Basic sulphate white lead, dry -- & 1 & D $82-24$ & Yes.. & (a), (d). \\
\hline & $\begin{array}{l}\text { Basic sulphate white lead, paste } \\
\text { in oil. }\end{array}$ & 1 & & Yes_- & (a), (d). \\
\hline 10 & $\begin{array}{l}\text { Zinc oxide, dry } \\
\text { Zinc oxide, paste in oil }\end{array}$ & $\begin{array}{l}2 \\
2\end{array}$ & $\begin{array}{l}\text { D } 79-24 \\
\text { D } 79-24\end{array}$ & $\begin{array}{l}\text { Yes... } \\
\text { Yes... }\end{array}$ & $\begin{array}{l}\text { (a), (d). } \\
\text { (a), (d). }\end{array}$ \\
\hline 11 & Leaded zinc oxide, dry & 2 & D $80-24$ & Yes... & (a), (d). \\
\hline 12 & $\begin{array}{l}\text { Leaded zinc oxide, paste in oil } \\
\text { Ocher, dry }\end{array}$ & $\begin{array}{l}2 \\
1\end{array}$ & $\begin{array}{l}\text { D } 80-24 \\
\text { D } 85-27\end{array}$ & $\begin{array}{l}\text { Yes. } \\
\text { Yes.. }\end{array}$ & $\begin{array}{l}\text { (a), (d). } \\
\text { (a), (f). }\end{array}$ \\
\hline & $\begin{array}{l}\text { Ocher, paste in oil } \\
\text { Ocher, paste in japan }\end{array}$ & $\begin{array}{l}1 \\
1\end{array}$ & $\begin{array}{l}\text { D } 85-27- \\
\text { D } 85-27 .\end{array}$ & $\begin{array}{l}\text { Yes... } \\
\text { No }\end{array}$ & (a), (f). \\
\hline 13 & Red lead, dry & 2 & D $83-24$. & $\begin{array}{l}\text { No.... } \\
\text { Yes... }\end{array}$ & $\begin{array}{l}\text { (a), (f). } \\
\text { (a), (c). }\end{array}$ \\
\hline & Red lead, paste in oil $\ldots$ & 2 & D $83-24$ & Yes... & (a), (c). \\
\hline 14 & $\begin{array}{l}\text { Lithopone, dry } \\
\text { Litbopone, paste in oil }\end{array}$ & $\begin{array}{l}1 \\
1\end{array}$ & $\begin{array}{l}\text { D } 208-26 \\
\text { D } 208-26\end{array}$ & $\begin{array}{l}\text { No... } \\
\text { No }\end{array}$ & (a), (d). \\
\hline 15 & Chrome yellow, dry & 1 & D $211-27$ & Yes.- & (a), (f). \\
\hline & Chrome yellow, paste in oil....- & 1 & D $211-2$ & Yes_- & (a), (f). \\
\hline & Chrome yellow, paste in japan.- & 1 & D $211-27$ & Yes. & (a), (f). \\
\hline 16 & $\begin{array}{l}\text { Lampblack, dry } \\
\text { Lampblack, paste in oil }\end{array}$ & $\begin{array}{l}1 \\
1\end{array}$ & $\begin{array}{l}\text { D } 209-26 \\
\text { D } 209-26\end{array}$ & $\begin{array}{l}\text { (1) } \\
(1)\end{array}$ & $\begin{array}{l}\text { (a), (f). } \\
\text { (a), (f). }\end{array}$ \\
\hline & Lampblack, paste in japan & 1 & D $209-2$ & (1) & (a), (f). \\
\hline 17 & $\begin{array}{l}\text { Bone black, dry } \\
\text { Bone black, paste in oil }\end{array}$ & $\begin{array}{l}1 \\
1\end{array}$ & $\begin{array}{l}\text { D } 210-26 \\
\text { D } 210-26\end{array}$ & $\begin{array}{l}(1) \\
(1)\end{array}$ & $\begin{array}{l}\text { (a), (f). } \\
\text { (a), (f). }\end{array}$ \\
\hline & Bone black, paste in japan...... & 1 & D 210-26. & (1) & (a), (f). \\
\hline 18 & Pure clirome green, dry & 1 & D 212-27 & (1) & (a), (f). \\
\hline & Pure chrome green, paste in oil- & 1 & D $212-$ & $\begin{array}{l}\text { (1) } \\
\text { (1) }\end{array}$ & (a), (f). \\
\hline & $\begin{array}{l}\text { Pure chrome green, paste in } \\
\text { japan. }\end{array}$ & & & (1) & (a), (f). \\
\hline 19 & Reduced chrome green, dry & 1 & D $213-2$ & $\mathrm{No}_{--1}$ & (a), (f) \\
\hline & $\begin{array}{l}\text { Reduced chrome green, paste } \\
\text { in oil. }\end{array}$ & 1 & & $\mathrm{Non}$ & (a), (f). \\
\hline & $\begin{array}{l}\text { Reduced chrome green, paste } \\
\text { in japan. }\end{array}$ & 1 & D 213 & No_- & (a), (f). \\
\hline 20 & $\begin{array}{l}\text { Chrome oxide green, dry } \\
\text { Chrome oxide green, paste in oil. }\end{array}$ & 1 & & (1) & (a), (f). \\
\hline 21 & $\begin{array}{l}\text { Chrome oxide green, paste in oil. } \\
\text { Prussian blue, dry. }\end{array}$ & 1 & & (1) & (a), (f). \\
\hline & $\begin{array}{l}\text { Prussian blue, dry } \\
\text { Prussian blue, paste in oil--...- }\end{array}$ & $\begin{array}{l}1 \\
1\end{array}$ & D $261-28$ & $\begin{array}{l}(1) \\
(1)\end{array}$ & $\begin{array}{l}\text { (a), (f). } \\
\text { (a), (f). }\end{array}$ \\
\hline & Prussian blue, paste in japan...- & 1 & D 261-2 & (1) & (a), (f). \\
\hline 22 & Ultramarine blue, dry & 1 & D 262-28 & (1) & (a), (f). \\
\hline & Ultramarine blue, paste in oil.-- & 1 & D $262-$ & (1) & (a), (f). \\
\hline 23 & $\begin{array}{l}\text { Ultramarine blue, paste in japan- } \\
\text { Aluminum powder for paints } \\
\text { (aluminum bronze powder), } \\
\text { dry. }\end{array}$ & $\begin{array}{l}1 \\
1\end{array}$ & $\begin{array}{l}\text { D } 262-28 \\
\text { D } 266-28\end{array}$ & No & $\begin{array}{l}\text { (a), (f) } \\
\text { (a), (d). }\end{array}$ \\
\hline 24 & Gold bronze powder, dry & 1 & & No.... & (a), (e). \\
\hline 25 & $\begin{array}{l}\text { Mineral iron oxide, dry } \\
\text { Mineral iron oxide, paste in oil-- }\end{array}$ & $\begin{array}{l}1 \\
1\end{array}$ & $\begin{array}{l}\text { D } 84-27 \\
\text { D } 84-27\end{array}$ & No... & $\begin{array}{l}\text { (a), (e), (g). } \\
\text { (a), (e), (g). }\end{array}$ \\
\hline 26 & $\begin{array}{l}\text { Iron oxide and iron hydroxide } \\
\text { paint, semipaste. }\end{array}$ & 1 & & Yes... & (a), (e), (g). \\
\hline & $\begin{array}{l}\text { lron oxide and iron hydroxide } \\
\text { paint, ready-mixed. }\end{array}$ & 1 & & Yes_. & (b), (e), (g). \\
\hline 27 & Black paint, semipaste & 1 & No.. & Yes... & (a), (d). \\
\hline 28 & Black paint, ready-mixed.-..... & 1 & & Yes... & (b), (d). \\
\hline 28 & $\begin{array}{l}\text { Green paint, semipaste-} \\
\text { Green paint, ready-mixed-- }\end{array}$ & $\begin{array}{l}1 \\
1\end{array}$ & No.... & $\begin{array}{l}\text { Yes... } \\
\text { Yes... }\end{array}$ & $\begin{array}{l}\text { (a), }(\mathrm{e}) . \\
\text { (b), (e). }\end{array}$ \\
\hline 29 & $\begin{array}{l}\text { White paint and tinted paints } \\
\text { made on a wbite base, semi- } \\
\text { paste. }\end{array}$ & 1 & No & Yes... & $(a),(e)$ \\
\hline & $\begin{array}{l}\text { White paint and tinted paints } \\
\text { made on a white base, ready- } \\
\text { mixed. }\end{array}$ & 1 & No_. & Yes..- & (b), (e). \\
\hline 30 & $\begin{array}{l}\text { Olive drab paint, semipaste---.- } \\
\text { Olive drab paint, ready-mixed }\end{array}$ & 1 & No & Yes... & (a), (e). \\
\hline 31 & $\begin{array}{l}\text { Olive drab paint, ready-mixed.-- } \\
\text { Outside white titanium-zine }\end{array}$ & 1 & No $N_{-. .}$ & $\begin{array}{l}\text { Yes..- } \\
\text { Yes... }\end{array}$ & $\begin{array}{l}\text { (b), (e). } \\
\text { (a), (e). }\end{array}$ \\
\hline & $\begin{array}{l}\text { paint, semipaste. } \\
\text { outside white titanium-zinc } \\
\text { paint, ready-mixed. }\end{array}$ & 1 & & Yes.-- & (b), (e). \\
\hline 32 & 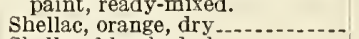 & 4 & D $237-29 \mathrm{~T}$. & Yes.... & (a), (d). \\
\hline 33 & Shellac, bleached, dry ............ & 2 & D $207-29 \mathrm{~T}$ & No_... & (a), (d). \\
\hline 34 & Varnisb, shellac.................... & 12 & Non-...... & Yes... & (b), (d). \\
\hline 35 & Varnisb, spar & 1 & No.... & Yes... & (b), (c). \\
\hline 36 & Varnish, inter ior & 1 & & Yes.- & (b), (c). \\
\hline 37 & Varnish, asphalt_................. & 1 & No_-_--....- & Yes...- & (b), (c). \\
\hline
\end{tabular}


TABLE 1.--Available specifications-Continued

\begin{tabular}{|c|c|c|c|c|c|}
\hline Item & Material & $\begin{array}{l}\text { Vari- } \\
\text { eties }\end{array}$ & A. S. T. M. & F. S. B. & Remarks \\
\hline 38 & Water-resisting red enamel...... & 1 & No.. & Yes... & (b), (c). \\
\hline 39 & $\begin{array}{l}\text { Interior lithopone paint, flat } \\
\text { and eggshell, semipaste. }\end{array}$ & 1 & No.. & Yos... & (a), (e). \\
\hline & $\begin{array}{l}\text { Interior lithopone paint, flat } \\
\text { and eggshell, ready-mixed. }\end{array}$ & 1 & & Yes... & \\
\hline 40 & $\begin{array}{l}\text { Gloss interior lithopone paint, } \\
\text { ready-mixed. }\end{array}$ & 1 & No_.- & Yes_-- & $(\mathrm{b}),(\mathrm{e})$ \\
\hline 41 & Putty & 2 & (1) & Yes... & (b), (d). \\
\hline
\end{tabular}

1 In preparation.

EXPLANATION

The numbers under the first column headed "Item" are not identification marks of either the A. S. T. M, or the F.S. B., but are identification numbers for this

paper only. given and $i$ nformation as to any different physical conditions specified.
The third column headed "Varieties" gives the number of varieties baving some specific difference in requirements. See specifications for details.

The fourth column " head" in A. S. T. M. speci-

In the fifth column headed "F. S. B." the word "yes" means that there is a Federal specification and the word "no" means that there is no Federal specif cation. "In preparation" means that a Federal specification will probably be adopted in the near future. No F. S. symbols are given because the marking and publishing system is being revised.

In the sixth column headed "Remarks".

(a) Material that is not uscd alone, but one that is used when mixed with other materials.

(b) Material ready for use.

(c) No samples necessary prior to contract or delivery

(d) Samples not commonly necessary prior to contract or delivery, but sometimes desirable. See specifications for details.

(e) Advisable to have agreed upon sample for color and appearance only. Qual. ity in other respects covered by rest of specification.

(f) A variety of colors and grades can be had under the specification, hence it is important to have agreed upon sample for color, etc., before making contract. See specification.

(g) Mineral iron oxide, paste in oil of A. S. T. M. is the same as iron oxide and hydroxide, semipaste of F.S. B. The A.S. T. M. specification covers the material as a dry pigment but not as mixed paint, while the F. S. B. covers a mixed paint but no dry pigment. A

\section{REVISION OF FEDERAL SPECIFICATIONS} Eighty-five Specifications Proposed for Revision Submitted for Comment and Criticism

Eighty-five revised specifications, proposed for the National Government, are now before the departments and others interested for comment and criticism. These specifications, in accordance with the scheme used with the Federal Standard Stock Catalogue, also bear the new designation. For copies of the proposed revisions or for further information pertaining to the specifications, address the Federal Specifications Board, care of the National Bureau of Standards, Washington, D. C.

\section{F.}

New designation

Lamps, electric, incandescent, large, tungsten-filament, with 1931 supplement Soap, toilet, floating, white

Fire-extinguishing liquid (carbon-tetracbloride base) . . ....

Hose, pnoumatic -

Oil, regetable, salad

Packing, a sbestos, valve-stem

Packing, asbestos, sheet, compressed

Packing, fiber, for lubricating and fuel oil

Packing, metallic, flesible

Packing, asbestos, rod, high-pressure

Packing, motallic, plastic

Packing, semimetallic

Pipe, welded-steel, black and galvanized Ink, writing

Ink, red

Linoleum, battlesbip

Linoleum, plain, inlaid, and printed

Aprons, rubber, surgeons

Tubes, colon -

Quicklime, for structural purposes

Potatoes, sweet

Onions

Cotton, absorbent

Hardware, builders' templat

General specifications for meta

reneral specifications for metals.............................

extile materials, general specifications, method of physical

Powder, insect, Pryethrum powder

Sodium-cyanide, for uso as an insecticide in fumigation....

Desks, wood .

Oleomargarine.

Nuts, assorted and mixed.

Coconut, prepared

Hops

Soda, bakin

Yeast.

6a Brushes, calcimine

\begin{tabular}{|c|c|c|}
\hline $\begin{array}{l}\text { F. S. } \\
\text { No. }\end{array}$ & Commodity & $\begin{array}{l}\text { New designa. } \\
\text { tion }\end{array}$ \\
\hline $397 a$ & Brushes, dust, coiling and wall.. & H-B-191. \\
\hline $399 \mathrm{~b}$ & Brushes, Fiteh, flat & $\mathrm{H}-\mathrm{B}-241$. \\
\hline $400 a$ & Brushes, sweeping, floor, hair & $\mathrm{H}-\mathrm{B}-651$. \\
\hline $401 \mathrm{~b}$ & Brushes, glue, round.. & $\mathrm{H}-\mathrm{B}-301$. \\
\hline $402 \mathrm{a}$ & Brushes, glue, flat....... & $\mathrm{H}-\mathrm{B}-291$. \\
\hline $403 \mathrm{a}$ & Brushes, lacquering, flat. & $\mathrm{H}-\mathrm{B}-351$. \\
\hline $404 \mathrm{~b}$ & Brushes, marking. & $\mathrm{H}-\mathrm{B}-371$. \\
\hline $405 a$ & Brushes, mottling -.- & $\mathrm{H}-\mathrm{B}-391$. \\
\hline $408 \mathrm{a}$ & Furniture and cabinets, office, sectional, steel & AA-F-791. \\
\hline 411 & Tableware, silver-plated & $\mathrm{RR}-\mathrm{T}-51$ \\
\hline $\begin{array}{l}412 \\
420\end{array}$ & $\begin{array}{l}\text { Paste, library and office } \\
\text { Wax, sealjng }\end{array}$ & $\begin{array}{l}N-P-101 \\
J J J-W-151\end{array}$ \\
\hline $477 a$ & Dosks, steel & AA-D-191. \\
\hline 485 & Gaskets, metallic-eucased & $\mathrm{HH}-\mathrm{G}-101$. \\
\hline $\begin{array}{l}538 \\
539\end{array}$ & Receptacles, waste-paper, fiber, office and lobb & LLL-R-191. \\
\hline 539 & $\begin{array}{l}\text { Erasers, steel } \\
\text { Goggles, oyocup...... }\end{array}$ & $G G G-G-501$ \\
\hline 543 & Goggles, welders' & $\mathrm{GGQ}-\mathrm{G}-541$. \\
\hline \multirow{13}{*}{$\begin{array}{l}544 \\
547 \\
553 \\
554 a \\
618\end{array}$} & Helmets, wolders' .... & \multirow{4}{*}{$\begin{array}{l}\text { GGG-H-191. } \\
\text { GGG-S-311 } \\
\text { QQ-B-101. } \\
\text { JJJ-M-791. } \\
\text { W-L-111. }\end{array}$} \\
\hline & 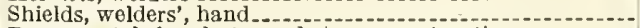 & \\
\hline & Bases, metal, for plaster and stucco construction & \\
\hline & $\begin{array}{l}\text { Lamps, electric, incandescent miniature, tungsten-filament, } \\
\text { with proposed } 1931 \text { supplement. }\end{array}$ & \\
\hline & Watchmen's-report apparatus.-.. & W-W-101. \\
\hline & Mold wash, silica............... & SS-M-501. \\
\hline & Facings, foundry, carbon-base & SS-F-111. \\
\hline & Enamel, pigmented (air drying and baking) black--.-.-- & $\begin{array}{l}\text { TT-E-521. } \\
\text { TT-B-601. }\end{array}$ \\
\hline & Chrome green, oxide & TT-C-231. \\
\hline & Lampblack & $\mathrm{TT}-\mathrm{L}-71$ \\
\hline & Ultramarine blue (dry, paste in oil, and paste in Japan) & TT-U-451. \\
\hline & Prussian blue (dry, paste in oil, and paste in Japan) & TT-P-691. \\
\hline & & \\
\hline
\end{tabular}

\section{BRITISH STANDARD COVERS ALUMINUM CONDUCTORS}

A specification recently issued by the British Engineering Standards. Association, and designated as No. 215-1930, refers to hard-drawn aluminum and steelcored aluminum conductors for overhead power transmission purposes. The publication is a revision of the 1925 edition of the specification, and differs from its predecessor mainly in that the value of the resistivity has been slightly altered in order to conform to the value recently adopted by the International Electrotechnical Commission.

The tables given in the specification have been recalculated in accordance with the new ralue of the resistivity. Provision has also been made for certain of the mechanical tests to be carried ont both before and after stranding. Slight modifications have also been made in the galvanizing test. 


\section{GASOLINE AND STEAM ENGINES IMPROVED THROUGH RESEARCH}

\section{Bureau of Standards Tests Fuels and Motors to Determine Most Efficient Equipment}

By Henry D. Hubbard, National Bureau of Standards

Soap bubbles were used by the Bureau of Standards in the experimental study of motor-gas explosions. The bubble is a constant pressure bomb and may be blown of the explosive mixture itself. On ignition its volume changes. The photographs of the expanding bubbles showed most vividly that the explosion is a beautiful and orderly phenomenon.

In another research very lean mixtures of gases were studied, too lean for an explosion to occur. Local combustion, however, was detected at low temperatures in a novel manner. The device was immersed in solid carbon dioxide snow so that when the oxygen and hydrogen burned locally the water formed by the combustion promptly produced microscopic crystals of snow.

In another research 31 clear quartz windows were set in the wall of a motor cylinder to observe visually how the flame advances from the point of ignition. In a later research a study was made of the number of molecules united as a result of each single spark. The number of molecules uniting was readily measured by the reduction in gas pressure after the spark. Here the place where ignition occurred was indicated by ice formation, the device being cooled by liquid air.

Available space is insufficient even to name the great number of researches of interest to the transport field. A probable cause of mysterious forced landings of planes is found in the so-called vaporlock gas bubbles in the feed line. A remedy recommended and applied was to specify a minimum distillation temperature which would eliminate gasolines too likely to boil in the fuel-feed line. Studies of gasoline energy wasted by rubber tires from poor design were reported to the industry as a potential national saving touching seven figures annually. The Bureau of Standards devised methods and devices for measuring such power losses and of testing the useful life of tires.

\section{Economic value of research.}

Of great economic significance, little known to the public, were the tests showing that low rolatility fnels were practicable for motors. As a result many millions of gallons annually were added to the potential supply of liquid motor fuel. Researches such as these lay sure bases for scientific advance in motor design and operation.

With notable advances in steam engineering-.the use of higher pressures, for example-the need for accurate data on the properties of steam became acute. The Bureau of Standards was asked to join in developing experimentally the numerical magnitudes of the thermal properties of steam as a basis for the reference tables to be used in research and steam engineering. This exacting research is completed and the results available for the public. The bureau's classic determinations of the properties of refrigeration aided greatly in bringing the era of refrigeration which we are entering. Similar accurate numerical data will make possible the development of the possibilities of steam, still the most widely used primary source of motive power for railways and shipping.

Numbers rule the world, and the measured data stated in numbers with high accuracy are the warp and weft of efficiency in the field of transport. The possibilities of the motor have no natural limit. To perfect it, however, the scientific bases must be established in the research laboratory with requisite accuracy.

The giant scales on which the great cargoes by land and sea are weighed, and ipon which weighings the collection of $\$ 6,000,000,000$ in freight charges is based, present an interesting problem in nation-wide standardization. In this enterprise, the Bureau of Standards sends it standard test car with 50 tons of standardized weights on a pilgrimage of standardization to test and certify the accuracy of the great track scales of commerce.

\section{Improvement in scales.}

Slow but notable has been the steady improvement in the accuracy of these scales, and concurrently charges are more just and dependable, to the mutual gratification of shipper and carrier. The bureau maintains near Chicago (at Clearing. Ill.) a master track scale depot, headquarters of the field work of testing track scales. Here 726 track scale test cars were adjusted to standard weight value in a single year.

For the operation and guidance of all types of transport facilities, measuring instruments are replacing the limited power's of the pilot or operator. On the switchboard of aircraft is a battery of measuring instruments, each giving some item essential to perfect flight. The Bureau of Standards has standardized some 40 such aeronautic instruments, giving the pilot measured data which his five senses, however keen and alert, could never detect. A recent device designed at the bureau gives warning when there is danger of ice forming on the plane, a real hazard and most dangerous between $4^{\circ}$ and $0^{\circ} \mathrm{C}$.

The rate-of-climb meter was a notable contribution. A new photographic sextant, devised to order for poJar flight, records the sun's position to within about five minutes of arc. An outstanding achievement of bureau experts, which won the Magellan medal to its inventors, is the earth inductor compass, more dependable under flight conditions than the magnetic compass. This instrument proved its success in the first airplane flight around the world, and industrial designers have since used the same principle and procured improved models for commercial use. 


\title{
NATIONAL WEIGHTS AND MEASURES CONFERENCE
}

\author{
Important Topics Affecting Measurements in Daily Trade Reviewed at the Twenty-third Annual \\ Conference
}

By R. W. Smith, National Bureau of Standards

The twenty-third annual meeting of the National Conference on Weights and Measures conrened at the National Bureau of Standards of the Department of Commerce in this city on June 3 and remained in session four dars. during which time many subjects pertaining to the regulation of commercial reighing and measuring derices were discussed, and codes of specifications and tolerances affecting such derices were recommended and adopted for uniform promulgation by the States.

\section{Specifications agreed upon.}

The most important actions of the conference centered around the rarious codes of specifications and tolerances for commercial weighing and measuring apparatus. Tro additions were made to the general specifications for weighing scales: Suitable antifriction elements shall be provided at all necessary points, and provision shall be made for adjusting the balance condition of all scales. Minor changes were made in the codes for liquid-measuring derices and lubricating-oil bottles. A complete code for odometers was adopted in tentative form. In amendment to the code for grease-measuring devices was adopted; the effectire date of the application of the code was postponed until January 1, 1931.

It is anticipated that the derelopment of a code of specifications for automatic-indicating scales will be given consideration for several years. The conference committee on specifications and tolerances was instructed to consider the question of a subcode under this general heading. to regulate the ubiquitous coinoperated person-weighing scales.

\section{Conference adopts resolutions.}

By resolution. the conference condemned the use of a new type of bottle used in dispensing lubricating oil at filling stations, garages, etc. This action was taken in the belief that the bottles are conducive to the perpetration of fraud. and the resolution further urged that all bottles used for dispensing lubricating oil be required to conform strictly to all requirements of the code previously adopted by the conference. The objectional type of botıle is tall and narrow, with the pouring spout usually integral with the bottle and not provided with rent to facilitate drainage. and not suitably marked.

The conference roted that a new calcium-chloride treatment for anthracite coal-designed to reduce dust when such coal is handled-is not objectionable from a weights and measures standpoint. prorided the treatment does not increase the weight per ton by more than 30 pounds. and provided that such coal is represented in advertising and billing as "chemically treated " coal. A resolntion indorsing the standardization activities of the National Scale Men's Issociation was also adopted, a report on lare-capacity railroad and industrial scales having proviously been made to the conference.

\section{Important activities.}

An important part of the national conference actirities is the consideration of general problems, such as weights and measures administration, new or improved methods for carrying on supervisory work, the results of special surreys or inrestigations, and reports of derelopments, new leoislation, etc

The program for the standardization of the cotton bale and the sale of cotton by net weight was discussed by Arthur II. Palmer. U. S. Department of Agriculture. 'This standardization, when effected, is expected to place American cotton in a more farorable position in foreign markets, and to directly benefit American cotton growers.

The suppression of fraudulent practices in connection with commercial weighing and measuring. formed the subject of a paper by J. M. Vanderslice. Philadelphia bureau of reights and measures.

H. S. Jarrett, State commissioner of weights and measures of West Virginia, discussed the scope and preparation of the annual report on official activities.

The possibilities of graphical treatment and analysis of data were demonstrated by Henry D. Hubbard. of the staff of the National Bureau of Standards. who traced the development of graphs and charts from the simplest form-the subdivided straight line-to the highly complicated 3 -dimensional solid graph, and then from assumed facts and figures showed the application of many of these forms to the presentation of statistical weights and measures data. For purposes of illustration, he used a variety of models. large-scale charts, and lantern slides.

The progress and derelopments during the preceding year along weights and measures lines, with particular reference to the Work of the Bureau of Standards, were reviewed from the Federal standpoint in the opening address of Dr. George K. Burcess. Director of the National Bureau of Standards, and president of the national conference. He also outlined the bills introduced into Congress dealing with weights and measures. A series of rerr interesting addresses included one by Dr. Julius Klein, Assistant Secretary of Commerce. who gave a picture of changing business conditions to-day compared with those of resterday. and emphasized the necessity of collaboration between business and industry, on the one hand. and gorernmental agencies on the other. if the commerce of the Nation-both foreign and domestic-is to keep pace with the swiftly changing conditions of the prescut era. Doctor Klein also stressed the fact that it is nanifestly difficult for the Government to deal with individuals, and that there must be a reasomable degree of or anization on the part of the busines interests of the country to provide chamnels through which conperation may be carrienl on. "Fortunately." sald Doctor Kilein. " the Imerican is a gregarions animal. and America is organization-minded. One of the rea- 
sons for the conspicuous leadership which we have established in the world of business is that very gregariousness; it is one of the reasons for our rapid recovery from the depths of disaster after the World War."

Hon. Randolph Perkins, chairman of the House Committee on Coinage, Weights, and Measures, spoke about standardization as an American characteristic. "What we are trying to accomplish," he said, "is to standardize tangible things to be weighed or measured. Standardization has resulted in the tremendous prosperity of the country. Practically all advancement of the world is based on weights and measures, because science depends upon weights and measures and progress depends upon science."

C. P. Norgord, of the New York State department of agriculture and markets, discussed in detail the efforts being made in New York to raise the standard of efficiency of all the officials engaged in weights and measures work.

Henry Lohmann, representing the National Association of Retail Grocers, urged the desirability of increased efforts to bring about the sale of commodities on a weight basis, particularly in the field of wholesale purchases made by grocers.

\section{Technical papers.}

Inspection of prescription scales, weights, and glass graduates in pharmacies as carried on in Detroit. Mich., was described by George F. Austin, jr., who urged every official to undertake such work at their earliest opportunity.

H. A. Spilman, U. S. Department of Agriculture, discussed the administration of the standard container act of 1928, a Federal law standardizing certain types of baskets and hampers used in the shipment of fruits and vegetables, which became effective as to its penalty provisions last November. "It has been found," Mr. Spilman stated, "that as interpreted, this law does certain things not contemplated by its framers, and efforts are now being made in cooperation with the National Bureau of Standards to bring about an amendment to the act so that existing State laws with relation to sales of fruits and vegetables by weight may not be interfered with."

By the terms of a statute recently enacted in New York, that State has effected standardization in the sale of logs by prescribing the use of a certain "log rule" to compute the number of board feet in standing or cut timber. Allen W. Corwin, sealer of weights and measures of Allegany County, N. Y., pointed out the amazing losses suffered when the sales of logs are based upon the "Doyle" rule, which has been commonly employed heretofore in New York.
J. C. 'Tinkey, deputy State sealer of Ohio, presented for the consideration of the conference the problem of the use of counter scales having "hidden beams"; that is, beams on the dealer's side of the scale and invisible to the customers.

The problems of the motorist received their share of attention by the conference with respect to the delivery of full measure in sales of greases, oils, and gasoline. The types of grease-measuring devices at present on the market for use at filling stations and garages were described by the author and methods were outlined for testing these devices to determine their accuracy.

Paul E. Hadlick, speaking in behalf of the petroleum marketers, asked the conference for a postponement of the recommended effective date of the code of specifications and tolerances for grease-measuring devices. After considerable debate, a six months' postponement was agreed to, as previously mentioned.

A demonstration of the measuring elements of seven makes of gasoline meters was conducted by representatives of the engineering staffs of several manufacturers, who explained the principles of operation and the methods of adjustment of their devices; they also disassembled the meters.

To insure full measure deliveries, A. W. Schwartz, assistant State superintendent of weights and measures of New Jersey, suggested that devices should be used to release any air which might become incorporated in gasoline prior to its measurement through a power-operated dispensing meter system. He recommended that the conference give attention to such devices and study their efficiency and possible necessity with a view to requirement by specification, if this course is found to be desirable.

Insurance against inaccuracies when petroleum products are delivered in truck tanks was considered in a series of three papers: Francis Meredith, director of standards of the State of Massachusetts, told of the testing of meters with which truck tanks are now being equipped, and through which all of the fuel oil or gasoline delivered must pass to be measured in this type of unit. In cases where the capacities of trucktank compartments are used as the basis for determining the amount of liquid sold, these compartments must be officially tested and approved by the weights and measures official. In some jurisdictions this is done by utilizing a carefully calibrated liquid meter, and this method was explained to the conference by H. N. Davis, of Vermont. Other officials make use of 100-gallon and 50-gallon standard measures, permanently mounted on a raised support, and calibrate the tank compartments by measuring water into them until the capacity of the compartment is reached. This method of test was described and illustrated by S. T. Griffith, Baltimore, Md.

\section{BRITISH SPECIFICATION FOR VANDYKE BROWN}

A revised edition of specification No. 319-1928, dealing with vandyke brown for paints, has been issued recently by the British Engineering Standards Association. After two years' experience in the use of this specification it was found that certain clauses needed modification in some small particulars, notably those clauses dealing with ash and volatile matter.

The form of the new specification follows that adopted in the previous issue. Clauses regulating the composition, together with standard acceptance tests for the purchase of the material, are given. Appendixes dealing with the standard methods for carrying out the tests are also included. 


\section{REDUCING ACCIDENTS AMONG AUTOMOBILE DRIVERS}

\section{Regulations to Determine Responsibility for Highway Mishaps Deemed Necessary to Safety; Enforcement Held to Be Prime Factor; Substitution of Ability to Stop for Miles per Hour as Measure of Legal Speed is Advocated

\author{
By H. C. Dickinson, National Bureau of Standards
}

Most accidents occurring on the highway are collisions either between vehicles or between a vehicle and a pedestrian. In such accidents at least two highway users are involved. If each of these users could know exactly what the other was about to do, and if each driver could stop before reaching the point of collision, such accidents would not occur. This may seem trite, but we believe it contains a most important basic idea.

Two general topics in existing traffic codes apply directly to the two essential conditions of safety noted above. The various right-of-way regulations are designed to make clear when and where each user of the road may and may not go. The various speed restrictions are designed to insure the driver's ability to stop general criterion of ability to stop, which shall apply at all times.

\section{Safe driving.}

A safe driver must know at every moment how much assured clear space there is ahead and that he can stop within it. Failure to know this or allow for uncertainties shortly must lead to a collision. This necessity has come to be such an intimate part of driving technique that its import seems to have been generally overlooked. It is here proposed to make use of this most basic of safe driving principles as a direct method of safe speed. A direct result of the adoption of this principle would be to educate inexperienced drivers as well as to regulate the reckless ones.
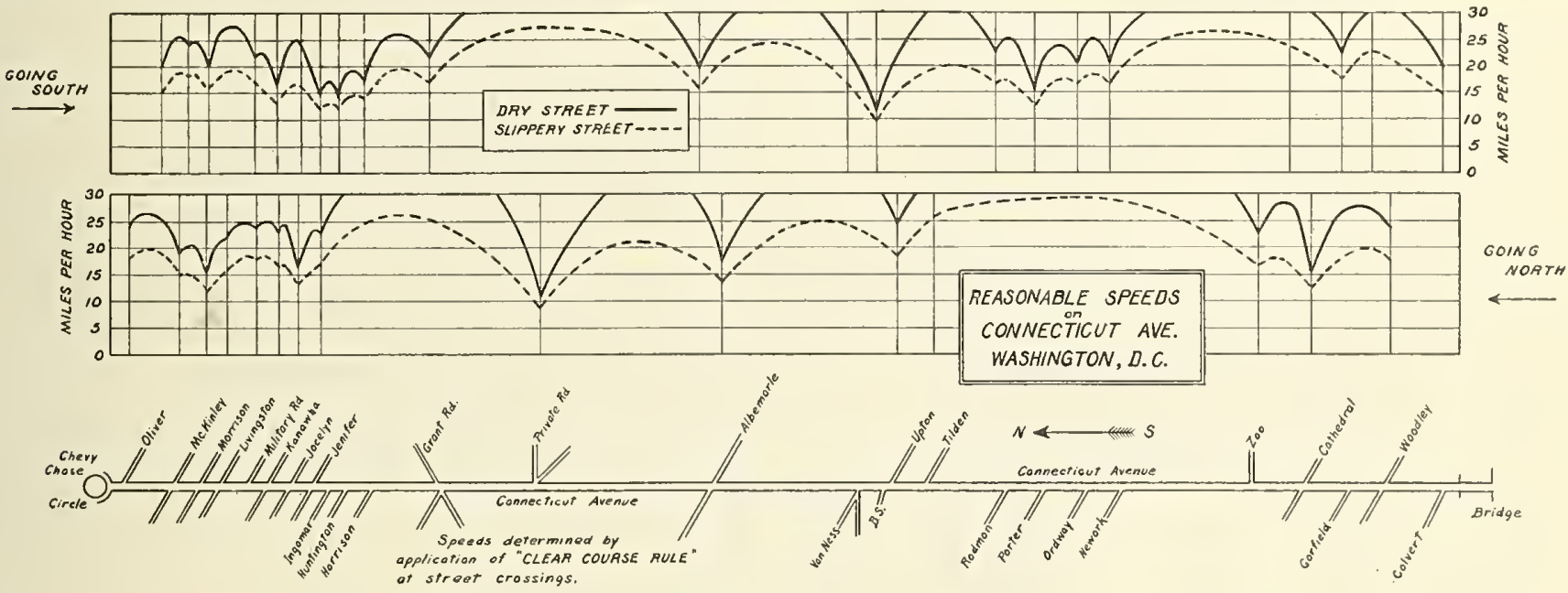

Chart showing the effect of intersections on the safe speed along a typical city strcet

in an emergency. If these two classes of regulations were effective, the accident toll would largely disappear; hence, the paramount importance of insuring the effectiveness of these two portions of the code.

First, since the main object of the driver is to make progress along the highway, it would seem logical to assume that the vehicle which is proceeding in its own traffic lane should have the right of way over vehicles making any other maneuver; in other words, a vehicle which is braking, turning, coming out from the curb, or crossing from one lane of traffic to another should do so with full regard to the right of way of through traffic. This is a general concept of right of way applicable to all conditions with suitable conventions as to intersections and in this respect differs from the rules now in force.

Second, since the safe speed of a vehicle depends upon many factors besides speed, such as brakes, road surface, skill of the driver, and so on, and since the distance within which a stop must be made may be anything from 5 to 500 feet, depending upon where a vehicle is and what is ahead, there is a need of some
The accompanying illustration shows the safe and practical speed on a 3.4-mile section of Washington highway on which the present legal speed is 22 miles per hour. The use of boulevard stops on some of the cross streets would increase safe speeds at some intersections. To avoid comment, we have omitted speeds exceeding 30 miles per hour, even where they are safe. This chart applies for an average driver and a car having good 2-wheel brakes and average acceleration. The full line is for dry-road conditions, and the dotted lines applies when the road is slippery. A uniform speed of 15 miles per hour on this stretch of road under some conditions would be reckless, while an average speed of 25 miles per hour regulated by ability to stop would be perfectly safe. With modern cars with good 4-wheel brakes the safe speed would be somewhat higher.

It seems clear that if ability to stop were substituted for miles per hour, as a measure of legal speed, we would have a sound general basis for meeting the second of the two essentials for safe driving. 


\section{Conditions can be met.}

The author is firmly convinced that these two conditions can be effectively met by a simple and readily understood codification of the principles suggested above. Such a suggested codification is given below without any attempt to introduce all the legal verbiage which might be desired, and omitting some explanatory items which might be needed. The several provisions in this code are so interrelated that they must
When to yield right of way.-When a driver or a pedestrian who is halted by traffic requires a vehicle to yield right of way, a signal shall be made witl the liand to the driver of the vehicle having the right of way, who, if sufficient distance is available for the necessary maneuver, shall signal his intent to yield the right of way and shall be responsible for acting accordingly. The driver or pedestrian having first signaled for right of way shall not proceed until his signal is answered. (Note, any person having sig-

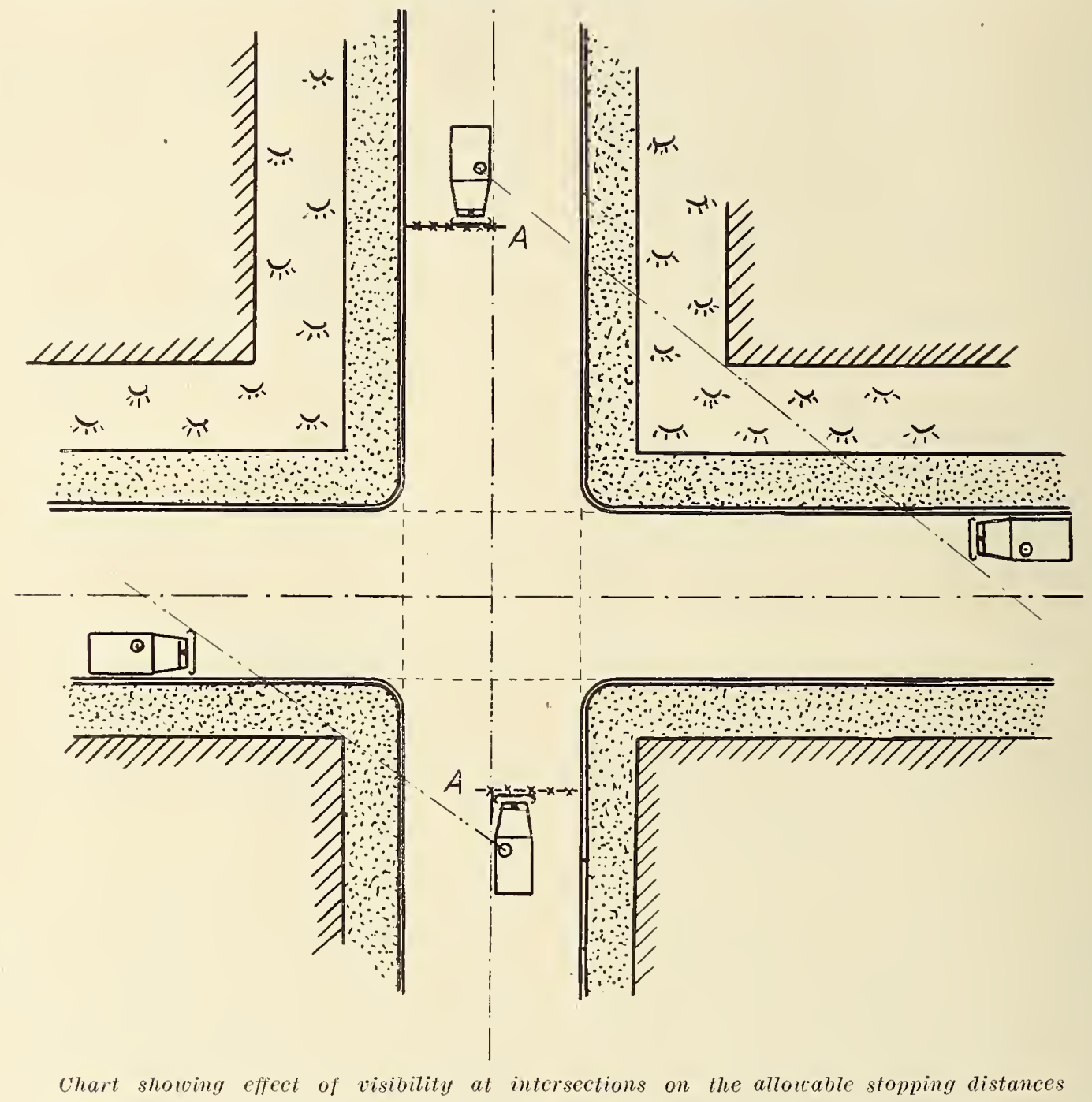

be considered in relation to each other rather than as independent items.

Right of way.-Right of way is defined as the right to uninterrupted progress within the legal speed. Except as noted below the vehicle performing any maneuver except proceeding within the legal speed at a reasonably uniform rate in a single traffic lane shall vield right of way to traffic so proceeding.

Exceptions.-At intersections the vehicle approaching from the left has the right of way. At crosswalks pedestrians have the right of way over vehicles. The right of way of any vehicle, person, or animal at rest in any traffic lane takes precedence over the right of any moving vehicle, subject to regulations governing highway obstructions. naled for right of way as herein provided may report as a matter of record the license number of a car failing to yield right of way. Habitual disregard of such signals by any driver as shown by such records from different complaints would be grounds for lisciplinary action.)

When vehicles are in motion in traffic the driver making any maneuver which may interfere with traffic on any traffic lane shall first signal his intent and make sure that the signal is seen and can be acted on.

Legal speed.- Under all conditions the legal speed shall be such that the vehicle can be brought to a stor, within its own traffic lane before reaching any point ahead at which there can be a legal obstruction in this traffic lane. Legal speed may be determined at desig- 
nated crossings or on any blind curves by an officer who may require any vehicle to come to a stop as provided hereafter. Should a collision occur between a vehicle and any object, this fact is prima facie evidence of illegal speed and hence of the responsibility of the driver. Proof that the object with which the vehicle collided was at the point of collision in violation of the right-of-way regulations shall be a defense.

\section{Notes and definitions.}

Traffic lane.-In the absence of lines or other highway markings, the traffic lane shall be determined as follows: On a 2-lane highway the traffic lane shall be the right half of the highway. On a 3-way lane highway the traffic lane shall be the right third of the parement, neither vehicle having the right of way over the other in the center lane except where special regulations are in force. On a 4-lane highway the two traffic lanes shall be the right and left halves of the portion to the right of the center. Thus a vehicle occupying the outside lane shall not encroach on the lane to his left except at his own risk, and the vehicle occupying the lane next to the center shall not encroach upon the right quarter of the pavement except at his own risk.

A driver may pass from one traffic lane to another. only at his own risk or by requesting right of way as provided herein. This applies to a driver also who is stopping, turning in either direction, coming out from the curb, or making any other maneuver aside from traveling at a reasonably uniform rate of speed in his own traffic lane.

Determining legal speed.-On any curve on the open road where the view is obstructed, an officer on the highway signaling a vehicle as it comes into view may require it to stop within its traffic lane before reaching his position. Failure so to stop will be a proof of illegal speed. (The situation here is exactly that of an unexpected obstruction, such as a stalled car or a group of pedestrians. Stopping under these conditions is imperative.)

At crossings where the view is obstructed a line may be marked on the pavement as follows: The illustration below represents an intersection obstructed by buildings. A line, $A$, is marked on the parement. such that a driver approaching the crossing will just clear the car approaching from lis left if both vehicles proceed at a uniform and legal speed. Similar lines may be drawn at all four approaches. A traffic officer may require any vehicle which seems to be exceeding the legal speed to stop on signal between the line, $A$, marked and the curb line.

Mounted police may require that all traffic keep to the right half of the paved highway except as required in overtaking other vehicles, and in particular that vehicles do not cross the center line on curves or at hill tops. Enforcement of these three provisions, together with definite responsibility for collisions, should keep the speed at all danger points down to safer limits than any miles-per-hour regulations, at the same time permitting reasonable speeds under conditions which are safe. where the road is straight and the view is clear. Speed at danger points, of course, can not be measured, since to make a measurement a uniform speed must be held for several hundred feet.

\section{Left-hand right of way at crossings.}

Some of the adrantages of this provision have been generally recognized. such as (1) the fact that once a vehicle has entered the intersection it has the right of way to proceed. (2) That it requires a vehicle to slow down before entering the crosswalk, thus tending to protect pedestrians. "There is another particular advantage which this system presents in connection with the traffic-control system here advocated. (3) When it is necessary to signal with the hand for a rehicle to yield right of way as here contemplated, such signal can be seen by a diver approaching from the left very much more readily than by one approaching from the right. If the system here recommended were adopted, overtaking on the right would be permissible on 4-lane highways, with entire safety, particularly if the traffic lanes were marked. It would be impossible on 2-larie highways, however, as at present.

Hand signals would be required only when requiring another vehicle to yield right of way. This would aroid useless signals which often become confusing, as does the present hand signal when a vehicle is making a right turn from the right traffic lane without slowing down.

\section{Summarization.}

The system here proposed is a consistent unit. It differs considerably both in form and in basic conception from present legal enactments, but it approaches much more nearly the existing practice of all safe and courteous drivers. It fixes responsibility definitely in substantially all cases, provided only the facts are known. The present system does not definitely fix responsibility in many cases even if the facts are known. The proposed system offers a definite criterion of legal speed in the most outstanding cases where speed is important. If such a speed provision were enforced, it would reduce speed at danger points and still might increase the average driving speed.

There are, of course, obvious objections to any traffic-control system; hence a fair conception of this one can be had only on a basis of comparison between it and present systems. We believe that there is no provision in the proposed system which would offer any serious difficulty in changing over from the present system. The only two provisions which appear at all radical are the left-hand right of way and the requirement that a hand signal shall be answered. As a matter of fact, the right of way at intersections is very seldom invoked and a clange could be readily made.

A similar change was made in the District of $\mathrm{Co}$ lumbia several vears ago from north and south bound traffic having the right of way to the present righthand rule, and there was no confusion whatever. As for the answering hand signal, the actual procedure is not greatly clatnged as the driver demanding right of way at present nearly always gets what is in effect an answering signal from the response of the other driver in slowing down or otherwise manipulating the vehicle.

The legal-speed provision is safe and we believe can be enforced where it is needed. No fixed speed limit which will be obeved is safe and no such limit can be enforced at danger points where slow speed is important, because the speed at any given instant can not be measured by an officer. 


\title{
STANDARDIZING ARMY EQUIPMENT
}

\section{Quartermaster Corps Concerned With Reduction of Superfluous Variety of Equipment; Standard Designs Promulgated for Army Supplies}

\author{
By Maj. Louis C. Wilson, Quartermaster Corps
}

The economic interests of the Government, so far as they lie within the scope of the Quartermaster Corps, are the basis for applied effort to standardize and simplify equipment and supplies procured for use by that branch of the Army service as well as such as is procured by it for use by other branches of the Army. This consideration which is in constant progress, with new vistas of opportunity frequently appearing, is best illustrated by concrete examples.

There is now nearing completion a study having in view a recommendation for the adoption of a standard type of rolling kitchen for use by troops in the field. At the outbreak of the World War there was, of course, a hurried period of preparation in connection with equipping vast numbers of soldiers, and in the matter of securing required quantities of rolling kitchens it was necessary to accept devices of various types and designs, because time did not permit of awaiting production of a standard type and design under the critical circumstances. Not only were these kitchens of varying kinds and patterns, but the appliances used in connection with them, such as the boilers and other incidentals and parts, varied and differed as did the colors in Joseph's coat.

Each kitchen required equipment and appliances peculiar to itself-each rolling kitchen was "on its own." After the war ended, there were, naturally, many of these rolling kitchens left on hand, and, from the viewpoint of economy, it was considered inadvisable to needlessly sacrifice them by sale bringing in returns only on a junk basis, consequently they were continued in use until they should become unserviceable.

\section{Standard type being developed.}

In the meanwhile, however, and in anticipation of synchronizing new procurement with a standard for devices of this kind, not only for peace time, but war time also, a careful study has been made of the entire subject in detail, and a standard model of rolling kitchen is being developed so as to embody the selected best features of all the war-time kitchens, and at the same time meet the varied requirements of the several arms and services which will use such model of rolling kitchen.

Upon the completion of the plans for, and thorough practical testing of, this device, the Army will, upon approval of the War Department, have an article all parts of which will be interchangeable, the equipment and utensils will be identical in form and size for all the kitchens in use, and this very essential item of equipment for providing food for the troops can be utilized as an animal-drawn or motor-drawn kitchen, or transported as a trailer, or even motor propelled. No matter what the transportation or other problem may be as affecting any particular arm of the military service, the rolling kitchen, as standardized, will lend itself to that requirement as well as to all others.

\section{Variety of machetes.}

As another illustration, take the item of machetes, a large heavy knife, 18 to 40 inches in length-used in the olden days of Spanish America for cutting cane, clearing paths, or as a weapon. Such a character of device has been, and is, a part of the prescribed equipment of certain arms of the military service, but heretofore under several different nomenclatures, although basically for the same general kind of utilization. Under the term "bolo" it has been a part of the equipment for the Infantry and for the Cavalry; under the title "hook, brush," it has likewise been in use by the Infantry; under the designation of "machete" it has been utilized by the Corps of Engineers; the Signal Corps has an instrument known as "knife, brush cutting." All these have been, as to designation and utilitarian application, combined under the general term of "machete, commercial, 22 ," with resulting practical application of economic principles.

\section{Simplifying equipment.}

Cartridge belts were, until study and action resulted in change, different for mounted troops from those designed for the dismounted troops. Under the desideratum of simplification and standardization, this practice has been discontinued, and one and the same design of cartilidge belt is issued both branches of the service-that issued the mounted troops including a cletachable pocket to meet the additional requirements of that particular service over and above the requirements of the dismounted troops.

Again, in the case of paulins and galvanized-iron cans, a number of various sizes were formerly used in each case, but the authorized sizes have been reduced to two, which takes care of all essential requirements and likewise standardizes the procurement and issue of such articles. Studies along other lines than those set forth above are now in progress, such as establishing one type of picket line for the entire service instead of separate types for individual arms, such as the Cavalry and the Field Artillery.

One of the most widely assorted items of supply used by the War Department is that of stationery and office supplies, which are stocked by quartermaster depots subject to requisition by the using agencies. If the Army were to attempt to stock paper of every color, quality, weight, and size, as produced commercially, or which the individual choice of some activity might express a desire for, it would result in tremendous loss of public funds due to waste and deteriorated stock, to say nothing of large sums being tied up in general, and in high prices being paid for relatively small lots. Therefore, the range of selections has been restricted to efficient operation and the items listed are the only ones stocked and issued. Allowance is made for technical requirements which can not be met from this normal list. 
A test is now being made in regard to canvas leggings, with a view to considering the adoption of a standard article in lieu of both canvas leggings and the spiral woolen legging now provided as a part of the soldier's equipment.

Many helpful suggestions, which will be the basis for consideration in this effort to standardize and simplify, have been and are resulting incidentally in the preparation of the recently directed Federal Standard Stock Catalogue, under the direction of Rear Admiral T. H. Hicks, U. S. Navy. The Quartermaster General supplies the data for the catalogne for all items with which the Quartermaster Corps has to do.

Many of the articles of Army equipment are produced by the Army at its own plants, including depots and arsenals, etc. Other classes of articles are obtained through contracts with commercial enterprises. Still other classes are such as have been produced, commercially, for sale on the market generally, but after production are purchased by the Army. One of the major items in the last-named class is that of subsistence, including, among other commodities, foods that are canned, bottled, or otherwise packed. Necessarily these are put up in a more or less numerous variety of sizes, supposedly within the lines of public popularity. There has been, comparatively recently, a get-together movement on the part of manufacturers of the same class of products with a combined movement to eliminate certain sizes, or rather to reduce the number of sizes of containers in order to apply the principles of simplified practice.

\section{Arny adopts simplified practice.}

The Army has recognized the practical wisdom of fitting in, so far as possible, with the commercial practices in this matter of food containers, and its specifications for subsistence articles have, during the past year or so, been carefully revised with this objective in view. There are, possibly, justifiable exceptions, but as a general rule it is recognized that to go beyond the lines of commercial production and purchase a special production of a standard article in a container which is not commercially standardized would, logically, result in a higher cost to the Government than if the usual commercial article were to be bought.

This same principle also applies to the food commodities themselves. These, so far as the Army, the Navy, and the Marine Corps are concerned, are covered by specifications promulgated by the Federal Specifications Board, and are mandatory upon the three military services named whose representatives make up the personnel of the provisions committee, which makes recommendations upon which the Federal Specifications Board bases its specifications.

\section{SPECIFICATION FOR ROOFING SLATE}

\section{Bureau of Standards Conducting Tests as a Basis for Federal Specification}

A few months ago the National Bureau of Standards was called upon by the Federal Specifications Board for information on roofing slate to form the basis of a specification for this material. After a study of the data available it was concluded that the information on weathering qualities was too meager, and the significance of various tests in this connection was not thoroughly understood.

It was decided therefore to make a study of weathered slates which had been in service for a considerable period of time to determine what weathering agents are mostly concerned in the destruction of slate roofs and what qualities in slate are most effective in resisting such destructive agents. Several hunclred samples were collected, some of which had been on roofs for more than 100 years. These were carefully studied to determine what alterations had taken place, especial attention being given to the decayed portions.

Slate, being a metamorphosed clay sediment, is composed largely of chemically stable elements. It is a very dense material with a higher flexural strength than any other common type of rock. With such properties it might be expected to be almost immune to weathering effects. Nevertheless it is evident that some slates can not be depended upon for more than 30 years of service on a roof.

\section{Frost action of no consequence.}

Frost action, which is commonly assumed to be very destructive to masonry, has been found to play a very small part in the weathering of slate. The decay of slate on a roof is confined mainly to the covered portions of the shingles and manifests itself by a slow process of crumbling and scaling in thin layers. Chemical and petrographic examination of the decayed portions reveal the presence of considerable calcium sulphate, although this compound is almost totally absent in the fresh slate. Some slates contain as much as 4 per cent of calcium carbonate which conld be converted to calcium sulphate by rainwater bearing traces of sulphuric acid.

This led to experiments on slate which involve a soaking in dilute sulphuric acid. Such tests on slates containing appreciable amounts of calcium carbonate caused a surface action similar to that shown on badly weathered slates, but underneath the thin layers so affected, the slate was still sound. This seemed to indicate that the action of sulphuric acid is not the only agent concerned in slate weathering.

Evidence of a hydration process has been found, and is now being investigated by the bureau. Soaking and drying tests have slown that some slates can be destroyed in 20 or 30 cycles of such treatment. While it is probably too early to draw conclusions, it scems likely that the hydration effects go hand in hand or, perhaps, precedes the decomposition of carbonates. 


\title{
ACCIDENTS IN THE HOME
}

\section{Eliminating Obvious Hazards in the Home Should Reduce Fatalities Amounting to 23,000 Annually}

\author{
By M. G. LLord, National Bureau of Standards
}

There are every year in the United States nearly 100,000 deaths due to accidental causes. The number' of injuries due to accidents is not so definitely known, but it has been estimated from the claims paid by insurance companies that there are about 200 nonfatal injuries for every death due to accident.

Accidents in the home are responsible for about one-fourth of the total fatalities. Of these deaths in the home about three-fourths occur to children under 15 years of age. Falls constitute the most numerous type of home accident.

When we realize that some citizen of our country meets death by accident on the average about every six minutes, night and day; that some one in our homes is injured by a fall every half minute; and that some other member of the houshold is, on the average, burned or scalded nearly as often-the great importance of taking steps to reduce this enormous toll and to standardize accident-prevention measures is irresistibly borne in upon us.

Accident-prevention work in industry has been going on for a great many years and is well organized. State labor officials and many others are constantly at work on the problem, and real progress has been made through the guarding of machinery and educational campaigns. In contrast with this, traffic accidents are on the increase. Less is known about accidents in the home, but their number is large enough to demand attention from those who are concerned with this sphere of human activity.

\section{Bureau conducts survey.}

The National Bureau of Standards has recently conducted a survey of accidents in the homes of members of the North Carolina Federation of Women's Clubs and in the Home Demonstration Clubs of that State. This was carried out through the cooperation of the General Federation of Women's Clubs. Reports were turned in up to May 7 covering 6,292 homes in that State. From these homes, 469 accidents of sufficient severity to interrupt usual activities were reported, or, on the average, 1 in every 13 homes. Of the reported accidents, 13 , or less than 3 per cent, resulted in fatalities, and all these occurred to children or to elderly people. There were no fatalities to persons between 15 and 55 years of age.

\section{HICKORY GOLF SHAFTS}

Printed Pamphlet on Commercial Standard Now Available

Commercial Standard CS18-29 Hickory Golf Shafts, has recently been received from the Government Printing Office. This pamphlet covers the semifinished product known in the trade as "B" form shafts. Moisture content, dimensions, and dimensional tolerances are speciefid together with a very practical test
Two-thirds of the fatalities occurred to children, and these were about equally divided between boys and girls. Four of the fatalities were due to falls, elderly ladies being involved in three cases. Eight of the fatalities were due to burns and scalds, and one was due to an infant choking.

Of the accidents reported, 240 , or more than half, were due to falls of one kind or another, such as sliding on rugs, stumbling on the stairs or at play. One hundred and twenty of the accidents, or 26 per cent, resulted in cuts or bruises of some kind. Sixty-eight of the accidents, or 15 per cent, were the result of heat, and consisted of burns or scalds.

\section{Accidents to women in lead.}

As might be expected in the home, accidents to females predominated over the accidents to males. During the period of life when the men are largely away from home during the day-namely, between 15 and 54 years of age-accidents were more than twice as numerous among women, and above 54 years they greatly predominate. On the other hand, below 15 years of age, accidents to boys predominate. Among the very young children they are almost equally divided between boys and girls. More than one-half of all the accidents in these North Carolina homes occurred to children under 15 years of age.

As a result of this survey, the General Federation of Women's Clubs proposes to undertake a campaign which will stimulate the women all over the country to take precautions which are generally overlooked, and to have an active part in the effort to prevent accidents in the future. It is hoped that each housewife will strive to avoid having her home constitute the unlucky thirteenth in which the typical accident occurs.

Many of the accidents which are daily taking place in the home are undoubtedly preventable. The elimination of obvious hazards; the instruction of children in proper methods of handling tools and toys; the placing of poisons, matches, vessels of scalding water, etc., out of the reach of little children; a campaign against carelessness; and many other precautions which are obvious from a study of reported accidents, should result in greatly reducing the unhappiness and suffering now caused in many homes.

for the determination of stiffness-the major requisite of a high-class hickory golf shaft. By this testing device shafts may be placed in four distinct grade classes, thus eliminating the controversy that was always imminent when stiffness was a matter of personal judgment ascertained by merely bending the shaft in one's hands.

Copies of this standard may be obtained from the Superintendent of Documents, Government Printing Office, Washington, D. C., at 10 cents per copy. 


\title{
COOPERATION IN REDUCING INDUSTRIAL ACCIDENTS
}

\author{
Chairman of Governor's Labor Committee of New York Explains Duty of Cooperation in Promoting Safety
}

By John Sullitan, Chairman, Governors Labor Committee, State of New York

Accidents in industry are preventable, and because of the vigilance of the department of labor, safety organizations, and factory preventive measures many thousands of accidents are prevented. It is true, nevertheless, that there are more than 300,000 such accidents each year in this great industrial State of New Tork.

Taking judicial notice of this sum total of death and maiming of humanity, Gov. Franklin D, Rooserelt, in cooperation with Industrial Commissioner Frances Perkins, has appointed a committee composed of representative wage earners to examine into this matter of accidents in industry, in an effort to find a way to reduce materially the resulting misery and the handicap to industry in the interruption in application of the skill and knowledge of his job that is always inherent in the workman familiar with his job and its processes.

No one any longer accepts workshop or constructionwork accidents as inevitable. At one time they were considered as acts or omissions of a Divine Providence. Now we are coming to recognize clearly that many of them are due to human improvidence. A particular accident at its first occurrence may involve no personal fault, but its recurrence in the same work place usually does. Where the fault is originally in the ways, works, or machinery its recurrence is plain negligence and thus becomes personal fault.

Without inquiring as to whether personal fault is attributable to either an employer or an employee, in any given instance, we can all join in the conclusion that personal fault can and should be corrected and stay corrected. Such a correction is a task of cooperation, and such corrective cooperation is a mutual duty.

\section{Cooperation necessary.}

If this great safety movement initiated by the governor of the State is to realize its possibilities, there must be the highest degree of enthusiastic support by all the human elements that enter into industry. Temporary support will not do. There will be required persistence if the objective is to be attained. The mere posting of safety warnings in work places will not bring the desired result. In the early days of inspection in the New York State Department of Labor orders issued did not make the desired impression. The wage earner knew from the way the inspector went about his task that he did not understand the technology of the shop; that he might be able to pass the civil-service examinations, but that he could not tell how the actual task of safeguarding was to be accomplished.

Fortunately that has been changed. The orders issued by the factory inspection bureau now not only have behind them the majesty of the law, but also the respect of the employee, who knows the law and knows that the inspector knows his job.

Safeguarding has become a science. Compensation has aided in its derelopment. The wage earner places great value on the compensation law. At the same time he knows from personal experience or from knowledge gained through association that it is much better to prevent an accident than it is to be paid two-thirds of his wages not in excess of $\$ 20$ a week.

For nrany years the accident toll in construction work has been very heavy, about 25 per cent of all compensated injuries. Perhaps a better security would result if we had a special and trained inspection force operating in this department. There seems to be much carelessness on the part of both master and mechanic; it may be the contempt that is associated with familiarity.

\section{Employers' indorsements.}

In many factories and other work places the sensible employer welcomes suggestions having to do with making the premises and the machinery safe. Some employers make it a rule to give consideration to all such suggestions; and if they are not practicable or are unnecessary, to explain just why that is so. This is one of the finest forms of cooperation. It is unfortunate that there are employers who, to their own detriment, resent such suggestions, and that they inspire the employees with the feeling that the employer does not care. I have just as strong condemnation for the employee who does not care, and who thus endangers the safety of his fellows.

If the governor's labor committee is able to reduce materially the sum total of industrial accidents, we will have much to be satisfied with. much to be proud of. It is also well to stress the fact that if we do succeed in reducing the number of accidents in this great industrial State, the way will then be open for material extensions and improvements in the provisions of the compensation law.

\section{FELDSPAR STANDARD ADOPTED BY INDUSTRY}

The commercial standard classification for feldspar has been enthusiastically approved by all branches of the industry, and the success of the project was accordingly announced in a circular letter from the division of trade standards to all those cooperating in the formulation of this standard.
The principle use of feldspar is that of a fluxing agent in the manufacture of whiteware, tile, etc. It is also finding increasing application in the manufacture of glass.

The uniformity of physical and chemical testing methods and the universal terminology and classifications embraced in the newly adopted standard should greatly facilitate the sale and use of this product for the consumers as represented in practically all lines of the ceramic industry. as well as the feldspar grinders. 


\section{DISCRIMINATION IN PURCHASING}

\section{American Home Economics Association Working for Significant Information on Household Commodities}

By Miss Alice L. Edwards, American Home Economics Association

Variety may be the spice of life, but the situation faced by the homemaker who wants to purchase bed blankets, as contrasted with that met, let us say, by the professor who buys a compound microscope for the zoology laboratory, is enough to produce a peppery outburst on the part of the homemaker if she realized her relatively unfavorable position.

The worthy professor is able to secure specific and reliable descriptions of the various microscopes available. Essential facts about important features, such as magnifications, adjustments, and attachments are provided, giving him ample opportunity to choose the instrument which best meets his need. Should corresponding information be available for the would-be purchaser of household commodities?

Many students of consumer problems are becoming convinced that this question should be answered in the affirmative; but before the essential information about blankets, for example, is made available, research on the problems involved will be necessary; and, furthermore, the consumer will have to convince manufacturers and retailers that she really wants and expects to be given information on significant points.

What does the homemaker need to know about the blankets she finds on the retail counter before she can make an intelligent choice? Probably the most important factors for her to consider are size, fiber composition, tensile strength, weight, and construction. Similar facts about the material nsed in the binding would be desirable, and, in so far as available, information about performance would be very valuable. Concerning each of these, useful data should be provided on the blanket label. Then, to secure the most satisfactory results, the homemaker should measure these known qualities and their combinations in different blankets against her own particular needs and choose the blanket which most nearly meets her requirements. Let us consider more in detail under the different headings the present situation and possible developments.

\section{Determining size and fiber composition.}

The size of the blanket is usually indicated on the label, and if it is not, can be readily determined. The purchaser's most frequent error in this connection is the selection of a blanket which is too short to tuck in securely at the foot of the bed and still reach up comfortably over the shoulders of the occupant. Since beds for adults are 6 feet or more in length, the standards which are being set up call for blankets at least 80 to 90 inches in length. 'The desirable width for a single bed should not be less than 60 inches and for a double bed not less than from 70 to 80 inches.

Some blankets car'ry a label guaranteeing that the fiber is all wool, others are labeled as part wool, while still others do not indicate anything about the fiber content. Here, therefore, the purchaser is often left to guess as to the composition or to trust to the word of a salesman, who may or may not have been given reliable information. Wool is a poorer conductor of heat than cotton; hence, a woolen blanket will tend to be much warmer than a cotton one of equal weight; it is possible to construct a cotton blanket so that it is as warm as a woolen one, but it will differ in air lermeability and absorption of moisture. Since cotton is much less expensive than wool, the mixed blankets now on the market usually have very little wool in them. It is possible for a blanket to be labeled as such a. mixture though its only wool is a single thread in the border. The amount of wool in mixed wool and cotton blankets in most cases runs between 3 and 7 per cent of the total fiber content, an amount conceded even by many in the trade to be too small to be of any value save as it affords opportunity to place the selling price well above that of an all-cotton blanket. Consumers should realize that unless they are insistent they will not be given specific information as to fiber content. They should demand this in justice to the honest manufacturer as well as to themselves.

\section{Ranges of tensile strength.}

The durability of a blanket depends largely on its tensile strength, a factor concerning which it is almost impossible at present to secure any information. In a very few instances do even the manufacturel's know the tensile strength of the blankets which they are making; and since the average customer can not afford to secure samples for testings, she remains totally ignorant save as she may be able to form some judgment from looking at and handling the blanket.

In the napping process the tensile strength of a blanket is often greatly reduced and unfortunately many very fluffy, attractive-appearing blankets have been unduly weakened by it. This is particularly true if the fiber is short or loosely caught in the yarn. Because of the strain on the warp during the weaving, these threads are always stronger than the filling threads. In recent reports on the physical properties of a number of blankets the tensile strength for the warp per inch ranged from 54.5 down to 17 pounds, while for the filling threads the figures ranged from 27 down to as low as 3 pounds. Think what would happen if in the laundering process such weak filling threads were called upon to carry the weight of the water-soaked blanket. These lower ranges of tensile strength are so inadequate that the blankets in which they are found can not be expected to wear for a reasonable length of time. Standards for tensile strength for blankets of different fiber composition should be established. Probably in no case should the minimum tensile strength of warp be less than 35 or 40 pounds per inch and of filling not less than 20 pounds.

\section{Construction important factor.}

At one time the weight of a blanket was considered a very important matter, and reasonably so, for a blanket of a given construction containing 6 pounds 
of wool would naturally be warmer and more durable than one similarly constructed and containing only 4 pounds. Of course, if the heavier blanket is made of cotton and the lighter one of wool, the weights can not be taken to show their comparative warmth. Some manufacturers and retailers are endeavoring to do away with the former practice of giving the weight, but it is hoped that the consumer will insist on this being given. It still remains valuable in comparing blankets known to be of similar fiber content. If, as is hoped, the practice of indicating fiber content becomes more generally followed by the trade, it will be very unfortunate to have dropped the practice of indicating the weight.

Durability is the characteristic of the binding which should be given most consideration. Certainly a lightweight china silk is wholly unequal to the wear to which a blanket binding is subjected. Moreover, the binding should not be applied in a manner nor the material be of such nature that it will shrink more than the blanket when it is laundered.

Durability, warmth, and ease of laundering are important factors in judging the performance of a blanket in use. How will the blanket wear? How warm will it be under usual conditions? How warm will it be on a camping trip when a cold breeze is blowing over the bed? How will its warmth be affected by laundering? WVill it fade, and how much will it shrink in the cleaning process? These are some of the questions which need to be carefully studied so that some means may be developed by which probable performance can be indicated to the buyer. Construction is important, as it has much to do with the durability of the blanket and also influences its warmth. 'Then, too, the effect of laundering on the appearance and warmth of the blankets in influenced by the construction. Certainly the properties of warp and filling threads and the tension to which they are subjected in the process of weaving should be such that certain stripes or portions of the blanket will not shrink when cleaned so as to give a puckered appearance.

Teachers of classes in textile buying might well discuss this movement with their students and discover the specific points on which local homemalers desire information. Progress in the standardization of blankets will be aided if home economists and all others interested will seek to inform themselves on the questions involved, and help to direct public demand in such fashion that manufacturers and retailers will recognize the consumer's interest in and probable use of information if this is made available. (Journal of Home Economics.)

\section{COMPOSITE BEAMS OF HOLLOW TILE AND CONCRETE TESTS}

Bureau of Standards Determines Value of the Tiles in Assisting Concrete to Resist Shearing and Bending Failures

In cooperation with the Hollow Building Tile Association (now the Structural Clay Tile Association), tests have been made at the National Bureau of Standards to determine the strength of composite beams and slabs of hollow tile and reinforced concrete. The tests were planned to obtain information on the value of the tiles in assisting the concrete to resist shearing and bending failures.

Sixty beams were fabricated and tested in the laboratories of the bureau. Forty-eight of those were composite beams consisting of either one or two reinforced concrete ribs similar to those in ribbed floors of concrete and hollow tile. The remaining 12 were concrete beams, each being similar in design and materials to the concrete portions of some of the composite beams. Some of each type were heavily reinforced for bending stresses and were tested in a manner to produce shearing failures; others were designed and tested to develop high compressive stresses in the concrete. All beams were 8 inches in depth; those for the shear tests were 6 feet 4 inches in length and from 4 to 29 inches in width, while those for the bend tests were 15 feet in length and either 8 or 29 inches in width.

The hollow tiles used in the construction of the beams for the shear tests were selected to provide data for the determination of the effect on the shearing strength of the physical properties of the tiles, their weight, and number of vertical interior webs. 'The bend tests were planned to give information on the effects of the weight, number of cells, and arrange- ment of the tiles on the strength of the beams in bending.

\section{Results sought.}

In the construction of the beams no atiempt was made to obtain specimens representative of commercial construction. On the contrary, the aim was to obtain specimens of uniform quality as regards the characteristics of the concrete and workmanship in order to minimize variations in the results from uncontrolled causes. All beams were kept damp for 28 days after construction and were then permitted to dry in the laboratory for approximately two weeks before testing. The average strengths of 6 by 12 inch cylinders representing the concrete of the beams were 2,720 pounds per square inch at the age of 28 days and 3,070 pounds per square inch at 42 days.

The results of the tests indicated that one row of iiles was equivalent in resisting shear to a concrete rib of the same depth and having a width of from 1.6 to 2.4 inches. These equivalent widths were greatest for the tiles made of the material of the highest strength and modulus of elasticity. However, the tiles made of the weaker materials usually had thicker shells which compensated in part for their weaker structure.

At loads considerably less than the maximum the tiles were more effective in increasing the resistance of the beams to bending deformations than at the higher loads. The relatively lower values for the higher loads are believed to be due, at least in part. to partial failure of the bond between the concrete and tiles. The results of subsequent tests indicated that the method followed in the construction and aging of the beams was not favorable to the development of as strong a bond as would have been obtained with other methods. 


\title{
STANDARDIZATION-SHOULD IT BE FEARED OR FOSTERED?
}

\author{
An Examination of the Principles of Standardization as Applied in Nature Points the Way
}

By I. J. FaIrchild, National Bureau of Standards

The term "standardization" is perhaps one of the most overworked and undervaluated words in modern usage. The inestimable comforts and conveniences made possible by standardization are so unapparent and so thoroughly a part of our everyday life that we give little heed to their existence and blandly accept them among the many other gifts of modern life.

If, however, we turn to the "good old days" when each railroad had its own idea as to the gage for its tracks, and its rolling stock was confined to its own lines; when one could never be sure that an electric bulb would fit a particular type of socket, and when the threads of automobile bolts and nuts were as different as the cars in which they were found, and a breakdown necessitated the services of a blacksnith, as well as a mechanic, we begin to see that standardization has, indeed, been made the servant of man.

Too frequently standardization is construed as meaning complete uniformity, and many are apprehensive lest individual expression and taste will give way to the sameness of housing, clothing, etc., which characterizes prison life. To allay any such forebodings we need only glance at the rich background of standards exhibited in the everchanging and fascinating field of nature.

To nature, the process of standardization and the evolution of standardized forms is an old, old story. Throughout the ages nature has standardized all individuals of the same species so as to be essentially alike, and at the same time fundamentally. different from individuals of other species. In the same species of plants, fishes, birds, or animals, individuals resemble each other in the minutest detail of structure and function. So thorough has nature been that every species may be recognized by the standardized organs, functions, characteristics. or habits peculiar to each.

\section{Standardization necessary to development.}

It is difficult to imagine any liuman progress without the wonderful standardization nature has provided; in fact, without the systematic and orderly influence of standardization, civilization would be impossible. Every item of existence would present a separate problem with no precedent for guidance, with no possibility for generalization, and, therefore, no possibility of knowledge which is based on generalization. There would be no organized life, no institutions. no custorns, no laws, for these depend upon an underlying limitation of action and reaction. There could be no medicine and no surgery, for how could it be predetermined where to look for the heart or the stomach, or, if you please, whether or not a given body contained such organs.

The more the mysteries of nature are dispelled by knowledge, the more is standardization revealed, as in the geometrical arrangement of crystal formation, predicted discoveries of new chemical elements, or the coming of a comet. We depend upon the meticulous regularity of the sun's appearance, the recurring phases of the moon, and the perfectly timed rotation of the planets. We accept as indisputable facts, the definitely established boiling and freezing points, the peculiar behavior of certain materials and the changeless normal properties of elasticity, strength, hardness, ductility, viscosity, refractivity, electrical conductivity, permeability, and other properties of the elemental things of nature which man is constantly appropriating for his use.

The variations of color arailable to the painter are composed of parts of a narrow band of spectral wave lengths and all of the artistry in music is conveyed through another small group of frequencies. And yet we hear no complaints that nature has carried standardization to extremes, that life is dull, drab, or stagnant as a result of standardized chemical elements, standardized crystalline growth, or wave lengths, as in sound, radio, light, and $\mathrm{X}$ rays.

The tennis player is confined to standards, such as the size, weight, and resilience of ball, dimensions of court, racquet and net, rules of the game, etc. The same is true of baseball, golf, and of every organized sport or athletic event.

The architect may be limited to two sizes of face brick, but he has a choice of color, texture, and arrangement sufficient to produce an unlimited variety of structures and effects, while the accomplished limitation of dimensions gives him a basis upon which to start, and relieves his mind altogether of the problem of the size of brick to be employed.

\section{Standardization found in every direction.}

In every direction we find standardization, whether we look to the orbits of the electrons about the atom, the constellations of the stars, the microcosm or the macrocosm, commerce or the arts, industry or sport. In the words of Albert W. Whitney, under the title "The Place of Standardization in Modern Life," in the May, 1928, isste of Annals of the American Academy of Political and Social Science:

There should be then a strong resemblance between the processes of nature and the processes of man *** and the part that standardization has played in nature should give us a very excellent idea of the part that standardization can play and should play in the world of human activity.

Thus, it is a natural and logical step for us to follow the precedents set by nature and apply them, for our mutual benefit, to the commodities of everyday trade since experience proves that controlled standardization is not to be feared, but fostered. Our concern, then, instead of frowning upon standardization as a growing threat to individuality. should focus upon a proper control of standardization in commerce and industry to the end that this greatest factor in our modern civilization shall continue to serve our best interests and shall not be permitted to run wild.

In order that industries may be encouraged to control standardization of their own commodities, a serv- 
ice is provided by the National Bureau of Stanclarcls, available on request, by means of an orderly and wellbalanced procedure to establish acceptable standards on a nation-wide basis.

A recent pamphlet describing this service entitled "The Commercial Standards Service and Its Value to
Business," sets forth a procedure whereby the Department of Commerce can be of assistance to industries desiring to set up standard nomenclature, definitions, grading rules, dimensional standards, or specifications as a basis for marketing. Copies are available on request.

\section{INDUSTRY TO STUDY STOCK SIZES FOR POLISHED COTTON TWINE}

Preliminary Conference of Manufacturers on May 28 Indorsed Proposal to Study Varieties of Products

A preliminary meeting of manufacturers of polished cotton twine was held in New York at the Harvard Club on May 28, under the auspices of the division of simplified practice of the National Bureau of Standards, in cooperation with the twine committee of the National Paper Trades Association, to consider the simplification of this commodity. Manufacturers rep. resenting more than 90 per cent of the total annual production were present or represented at this meeting.

The need for simplification of polished cotton twine was discussed at a joint meeting of manufacturers and distributors held in New York in February, 1930. Following this meeting, an important manufacturer, in requesting the division of simplified practice to call a meeting of manufacturers to consider simplification, summarized the situation as follows:

At present we believe twines are produced in as many as $\delta$ to 10 different qualities, and if the number of qualities to be produced could be narrowed down to, say, only 4 definite, distinct ones, it would enable the manufacturers to produce each of the various qualities more cheaply. Another one of the drawbacks to good production, and something which, at the present time, is responsible for excessive expense, is a matter of put-up, such as balls, tubes, cones, reels, etc. There is no standard for the weights that these styles of winding shall have. Some of these put-ups are very expensive to make, and undoubtedly could be eliminated. We would find it difficult to suggest any particular standards which would be applied to the cotton-twine trade; but we do feel that if the various manufacturers could be brought together to consider this whole matter, that a much more simplified schedule of production could be had, which would result itself into lower costs to the manufacturer as well as the consumer. To this end we urge that your division inquire of other manufacturers their opinions on this matter : and if they find there is sufficient interest to offer a fair chance of success, to call a meeting of those manufacturers for the purpose of going over the situation carefully, and the apjointing of a committee to draw up a tentative plan of simplified practice for the approval of the group.

'Those attending the meeting of May 28 were unanimous in their opinion that there existed a need for simplification, and all offered to cooperate in the development of a program. A simplified practice committee was appointed, as follows: W. E. Penny (chairman), of the Cayuga Linen \& Cotton Mills, Aubun. T. I.; IT. D. Anderson, of the Bibb Manufacturing Co., Macon, Ga.; E. S. Pratt, of the Samson Cordage Works, Boston, Mass.; and George Underwoor, jr.. of the Auburn Converting Co., Auburn, N. Y. The committee will prepare a survey form which will be sont to all manufacturers for certain data which it was agreed would be necessary as a basis for a tentative schedule. The division will send out this survey form when completed by the committee, and will compose a combined report of the information thus received. This combined report will form the basis for discussion as to a future conference.

\section{RESEARCH ON PURIFIED WOOD FIBERS}

\section{Bureau of Standards Is Making Tests on Purified Wood Fibers}

The buyer of certain kinds of paper is greatly interested in the probable durability thereof. The life of paper is affected by three factors-the material of which the paper is made, the process of manufacture, and the storage conditions to which it is subjected. The first of these three factors may be further broken down into the kinds and amounts of fiber and of other ingredients, such as sizing materials used to make the paper water resistant.

Before a standard for permanence can be set up it is necessary that the effects of all of these three factor's be well unclerstood. An investigation of the properties of papers made from purified wood fibers, with different kinds and amounts of sizing, is now under way. A number of tub-sized papers were prepared in the Bureau of Standards paper mill, and these papers are now being subjected to the various permanence tests. Three basic papers of purified wood fibers. were tub sizecl. These were: (1) A waterleaf paper, (2) a paper sized with one-half per cent rosin, (3) a paper sized with 1 per cent rosin. Each of these basic paper's were tub sized with the following: (1) glue, (2) glue and alum, (3) starch, and (4) starch and alum.

The testing is under way on all these papers, but sufficient data are not yet available to draw many conclusions. The basic papers and most of the glue-sized papers have been subjected to the 72 -hour heat test. The stability of the papers, as indicated by the retention of their physical strength properties after heating, is very high. The retention of glue, in the case of papers tub-sized with glue, has not been determined as yet, but the sizing has resulted in all cases in expected increase in folding endurance, bursting strength, and tensile strength. It is interesting to note that the base paper sized with only one-half per cent rosin appeared to be sufficiently well sized. The possibility of using such a small amount of rosin for the effective sizing of papers from this type of fiber is of importance from the standpoint of lelative permanence.

In the case of starch-sized papers the amount of starch retained was found to be in proportion to the absorbency of the basic paper. Thus the waterleat sheet retained the most, about 2 per cent; the paper sized with one-half per cent rosin retainer about 1 per cent starch; while the paper sized with 1 per cent rosin retained about three-fourths per cent starch. 'Tub-sizing with starch also resulted in the oxpected increases in strength. 


\title{
STANDARDS OF SERVICE IN THE ELECTRICAL INDUSTRY
}

\author{
Accurate Measurements and Codes of Practice Give Definite Basis for Commercial Relations
}

By E. C. Crittenden, National Bureau of Standards

An earlier article in the $\mathbf{J}$ une issue of this journal described work of the National Bureau of Standards affecting materials used in the electrical industry. The bureau has two other general lines of work which affect more directly the actual service rendered and the relations of the electric power industry with the public. 'These are methods of measuring the service, and standards of practice to be followed in rendering it. for the determination of the correct values of the ampere and ohm, from which the volt and watt would follow. At the same time it has been carrying on negotiations for international action in correcting the old units.

Much study has also been given to the laboratory standards by which the values of the units are maintained when they have once been established.

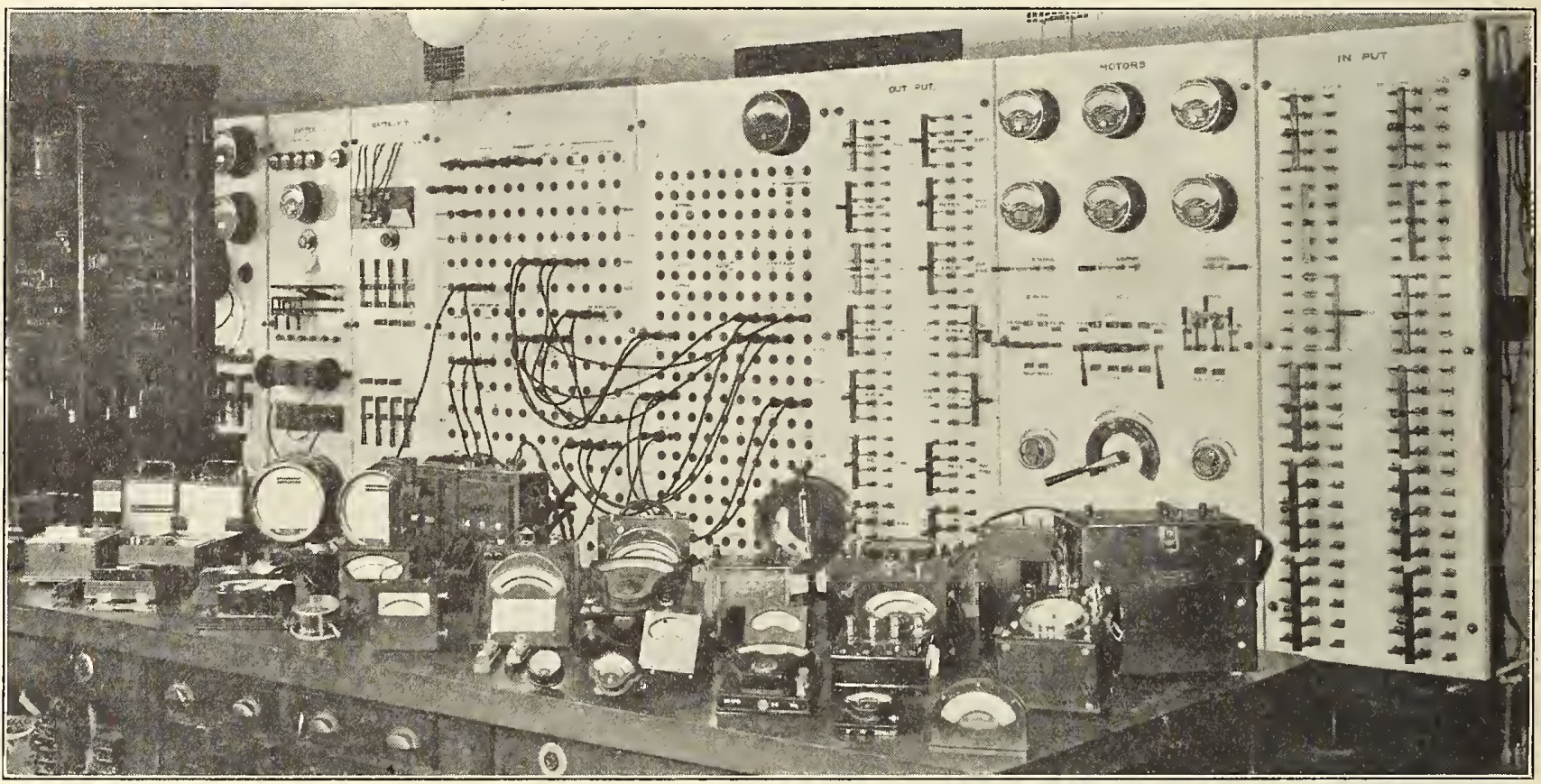

Typical electrical instruments tested by the Bureau of Standards, and distributing panel for power supply to instrument testing laboratories

The primary function of the Bureau of Standards is to supply the means for accurate measurement, and this function it has endeavored to fulfill both for scientific and for commercial purposes.

Basic standards for electrical measurements.

The first step necessary is for the burean itself to have highly accurate standards. Electrical units of measurement are derived originally from mechanical forces exerted by the electric current. In ordinary machines these forces are tremendous, but they can not be calculated with high accuracy.

Special devices made to the most exact dimensions and built of the purest obtainable materials must be used to determine whether the practical electrical units have the correct values. In spite of the care with which this has been done in the past it is now known that there are errors in the units large enough to be significant in some engineering work. For several years, therefore, the bureau has had skillful experimenters designing, building, and adjusting new devices

\section{Standards for industrial and commercial measure-} ments.

It is not sufficient, however, for the bureau itself to have highly accurate standards and instruments. There must be ways provided to carry over this accuracy in such degree as may be practicable to the operations of commerce and industry.

Every meter used in the sale of electricity in this country has its scale of measurement derived directly or indirectly from the standards of the bureau. In order to make this possible, standard instruments are calibrated, first, for the manufacturers who produce the meters; second, for utility companies which are usually required by State or municipal regulations to check their meters at specified intervals; and finally, for the State public service commissions which usually check the measurements of the companies and make special tests on meters concerning which complaints are made by customers. 


\section{Improved methods for calibrating transformers.}

The bureau also tests the various types of instruments which are used by electric companies in the control of their own operations, an , in the measurement of power interchanged between companies. The growing magnitude of the electric power industry continually calls for new instruments of larger range.

The bureau has devised improved methods for the calibration of the instrument transformers used in the measurement of electric power in large amounts, and it calibrates these transformers as well as the instruments that go with them. New instruments for the accurate measurement of electric currents up to 12,000 amperes and of voltages up to 300,000 are now being built in the bureau's shops.

\section{Standards of practice.}

The standards of practice for which the bureau is sponsor are developed with the cooperation of all interests affected by them. They serve as guides to good practice in industry.

Some are supplied chiefly by voluntary action of those affected, while others are codifications of requirements suitable for legal enforcement by States or cities. The bureau itself has no authority to apply or enforce these codes, but their widespread acceptance by State utility and industrial commissions has helped greatly in furthering uniformity of regulations, as well as in making them reasonable and adequate.

The standards of this class which affect electric service most directly are Standards for Electric Service, the Code for Electricity Meters, and the National Electrical Safety Code. The first includes a compila-. tion of actual State and city regulations regarding electric service, a discussion of the elements which must be considered in determining the adequacy and safety of such service, and drafts of regulations and ordinances which are recommended for use by States, cities, and towns.

The Meter Code is a joint project of the bureau, the Association of Edison Illuminating Companies, and the National Electric Light Association. It gives complete specifications for the testing and acceptance of types of electricity meters and prescriptions for their proper use.

The Electrical Safety Code is a very complete set of rules to be observed in the generation, distribution, and use of electric power, in order to make the service as free as possible from hazards to persons.

The bureau has also published a Code for Protection Against Lightning, one part of which deals with protection of electrical circuits and equipment.

\section{Assists in periodic revisions of National Electric Code.}

In addition to these codes for which it has primary responsibility, the bureau also takes an active part in the periodical revisions of the National Electric Code, which is prepared by a committee under the auspices of the National Fire Protection Association, primarily for the purpose of minimizing fire hazards. 'This code includes detailed requirements for electrical wiring in buildings and is the basis of most of the legal regulations on this subject. It is therefore of rital importance to the whole electrical industry, and numerous committees are continually at work in perfecting it and revising its rules so as to encourage the best practices in wiring. The Bureau of Standards is represented on 12 of these committees and furnishes chairmen for four of them.

Similarly, through committees of various engineering societies and trade associations, the bureau helps in the development of many other standard codes and specifications which find application in the electrical as well as other industries.

\section{PERFORMANCE CHARACTERISTICS OF 2-BLADE PROPELLER FANS}

Tests at Bureau of Standards Develop Important Data for

Some time ago an investigation was undertaken of the performance of 2 -blade propeller fans, to obtain data needed by industry. Recently there has been a trend toward the use of fans of this type in coolingtower installations, and their use has been considered for other applications where it is desired to move large volumes of air against relatively low pressures. Since no data were available as to the operating characteristics of 2-blade propeller fans, the importance to the manufacturer and user of obtaining this information is obvious.

Seven 2 -blade propeller fans, 8 feet in diameter and of pitch diameter ratios $0.250,0.375,0.500,0.625,0.938$, and 1.063 , respectirely, were tested at the National Burean of Standards under operating conditions approximating those encountered in cooling towers. Each fan was operated at constant speed of rotation against resistance conditions which were varied by steps, from a completely blocked passage to as nearly an open passage as the conditions in the test duct permitted. The volume of air mored in unit time, the head developed, and the power absorbed by the fan were determined for each resistance condition. Data were obtained for two conditions of operation, ( 1 ) with the fan operating as a blower, and (2) with the fan exhausting air from the test duct.

\section{Results obtained.}

The results mere expressed in the form of coefficients and plotted to facilitate their use in estimating the performance of fans of other diameter's and of other rotational speeds.

The chief effect of variation of pitch diameter ratio is to increase the range of the head and volume coefficients with increase in pitch diameter ratio, up to pitch diameter ratio of 0.938 . Pitch diameter ratios greater than 1 should not, in general, be used.

Two-blade propeller fans are suitable for moving large volumes of air against pressures that do not exceed 1 inch of water. For pressures greater than 1 inch of water the rotational speeds become inconveniently large. The speed of rotation and the fan diameter should be carefully chosen to obtain maximum efficiency. 


\title{
STANDARD SPECIFICATIONS FOR ROAD EQUIPIENT
}

\author{
Highway Department Official Reviews Value of Standard Specifications for Purchase of Road-Building \\ Equipment
}

3y W. A. VAN DUzer, Assistant Chief Engineer, Pennsylvania Department of IHighways, and President Ameriean Road Builders' Association

If the specifications covering supplies, material, and equipment used by the different highway authorities could be standardized, we believe the benefits derived would more than recompense the effort and expense necessary to bring about such standardization. It is, of course, obvious that the large majority of purchases, especially in the equipment line, can not be completely standardized, neither do we believe it would be advantageous to carry standardization too far as it would have a tendency to retard improvement in designs.

No one would care to make the statement that any particular design is the acme of perfection and does not offer opportunities for improvement. However, there are many items which, it is believed, could be standardized and from which standardization, much benefit would be derived. Among these benefits are the following: The manufacturers, knowing that the different States would require materials covered by the same specifications, could manufacture such materials throughout the year, stocking them during the dull seasons. This would have a tendency to stabilize industry and would permit a more economic production which should be reflected in the purchase price. If materials were standardized, deliveries could be made promptly, and costly delays would be avoided. In case of emergencies the highways departments would be able to obtain material meeting their specifications and requirements. At present it is often impracticable to wait until such materials can be obtained, and consequently substitute and often inferior materials are accepted in order that the work may not be delayed.

\section{Value of Standardization.}

By promulgating standard specifications better materials or equipment can be obtained. As an example of this, we would cite the 10-gallon caretaker's heating kettles, as they were sold by the leading supply houses four or five years ago. These kettles were made of light-gage sheet steel which was too thin to lend itself to welding. Consequently, the spouts and seams on these kettles were riveted and almost invariably leaked when new. In addition to this, the kettles were so light that a rough handling soon had them out of shape and unserviceable. About four years ago we drew up specifications increasing the gage of the metal and specifying that all joints should be welded. Practically all the manufactures's adopted these specifications, and now the heavier kettles can be purchased from any of the supply houses handling this class of equipment.

Another example where standard specifications have been of benefit is on road drags. For years we purchased road drags on competitive bids. Different manufacturers had special points about their particular drags that they emphasized which were good, and others were merely talking points. Two years ago we went into this matter carefully and made a drawing of a standard road drag. In doing this we embodied the really worth-while points in all the drags adding weight and strength where required. We submitted these drawings to the different manufacturers of drags and obtained competitive prices. The drags we purchased cost very little more than we had been paying for an inferior product, and not only gave us a very efficient drag, but also gave us drags where all parts were interchangeable, and as soon as the entire State is equipped with these drags confusion relative to the purchase of drag blades and repair parts will be a thing of the past.

\section{Variety of Equipment.}

Speaking of drag blades brings up the point of cutting edges for graders. A survey about two years ago showed that while we had graders with four different lengths of blades, it required 54 different cutting edges to supply our needs. This was due to the different shapes and different punchings as furnished by the various manufacturers of r'oad graders. About that time we adopted the standard as recommended by the standardization committee of the Mississippi Valley Association of State Highway Departments. All graders purchased now are equipped with mold. boards punched to take these cutting edges. As soon as our old machines are worn out the purchase of cutting edges for graders will be simplified.

Another class of equipment that lends itself well to standardization is snow fence. At present practically the only difference in the specifications of different States covering snow fence is that some of the States specify No. $121 / 2$ while other's specify No. 12 . There is also a slight difference in the test of galvanizing on this wire. Consequently, snow-fence manufacturers, of whom there are only five or six in the country, are linable to manufacture fence for the different departments until they have been definitely awarded the contracts. This often leads to delays in furnishing this equipment. We minimize these delays by advertising carly in the year; usually in June. However, if the different States had the same specifications we are often quite sure that we would obtain better prices, jrompter deliveries, and that the manufacturers would be better satisfied.

This also might apply to corrugated pipe. At present pipe manufactured to the specifications of some States will not be accepted by Pennsylvania due to the specifications relative to riveting and width of the lap. Consequently, if we require pipe on short notice we often are compelled to wait until such pipe can be fabricated, while if the specifications of the different States were standardized such pipe could be shipped directly from stock. 
The specifications covering crushed stone, as promulgated by the different States, give a good example of wasted effort and money on the part of the stone producers. For instance, producers who are shipping interstate business and hare orders for two or more States must change their screens in order to meet the grading requirements of the different States. They do not dare to stock a large quantity of stone for fear they will not be able to dispose of it. Yery few of the sione producers have space to stock different sizes as required by different States.

\section{Specifications should be coordinated.}

We see no reason why specifications corering bituminous materials for surface treatment, penetration, etc.. can not be standardized; and there is every reason to believe that if they were. the highway departments, as well as the producers of such materials, would be mutually benefited. The same applies to paints used especially for highway purposes, such as traffic paint, guard-rail paint, sign paint, etc.

In the higher class of equipment, such as trucks, standardization is rather a difficult problem to solve. We hare standardized on dumping equipment for manually operated dump bodies. The principal idea being to obtain a dump body that will be safe in operation or, in other words, one that can not run down and injure the operator by a flying crank or wheel. Three rears ago, when we insisted on this type of equipment, there was only one manufacturer who produced a dumping arrangement that met our specifications. However, to-day there are at least four that comply with our specifications with regard to safety.

On various other items of equipment we realize that complete standardization is impracticable. In drawing specifications for such equipment it is our practice to draw specifications sufficiently tight to exclude equipment we know is not suited for our purpose and sufficiently open to accept all other equipment. This we believe should be the purpose of all specifications. To-day there has been very little concerted effort on the part of the different highway departments to at- tempt standardization or to cooperate, or to coordinate. in the promulgation of specifications.

We believe that if the testing division. the equipment division, and the purchasing divisions of the different States would gire this matter careful and serious consideration that much benefit would be derived. At first it might be opposed by the manufacturers, but we believe if the matter was properly handled their objections could be orercome by the potential benefits to be derived by them through such standardization.

\section{Road builders interested.}

The American Road Builder's' Association, recognizing the benefits to be derived from standardization of purchase and standardization of equipment models, appointed a committee about two years ago to work in conjunction with a similar committee appointed by the Associated General Contractors of America to work out a depreciation schedule on equipment. This committee made a progress report at the annual meeting of the American Road Builders' Association in 1929. showing the rates of depreciation on practically all kinds of equipment used in highway construction. The final report was made at the Atlantic City meeting of the association last January, and these schedules are now arailable.

The American Association of State Highway Officials and the American Road Builder's' Association appointed a joint committee, of which the writer was chairman, to work out a method of standardization of purchase. A report was made last year and the committee will continue during the coming season. There was also appointed a joint committee of the American Association of State Highway Officials and the American Road Builders' Association, to standardize the construction of weighing derices for fine and coarse aggregates for concrete, which has been adopted as standard by the two associations.

It is proposed during the next year to continue these studies and make recommendations which will help the equipment manufacturers as well as the road authorities in determining set standards for each piece of equipment used in highway construction.

\section{AMERICAN NATIONAL SPECIAL SCREW THREADS}

\section{Industry Adopts Recommended Program}

The 12-pitch thread series recommended by the National Screw Thread Commission has been followed by some producers and users for several years where a certain pitch is essential for a range of sizes, as in railroad practice where worn stud holes are rerguired to be retapped or in machine construction where thin nuts are used on shafts and sleeres.

While the recommendations of the National Screw Thread Commission are mandatory upon the WTar ant Nary Departments and as far as practicable apply also to purchases by all Gorernment departments, it seemed desirable to determine the extent to which these standards were being applied by the industries concerned. Accordingly, at the reguest of the National
Screw Thread Commission, the National Bureau of Standards circulated Section II of the National Screw Thread Tables for Shop Use--Special Threads. to the industry to determine the extent of adoption and use of these recommendations in industry.

As a result of this circulation a satisfactory majority of written acceptances have been receired and announcements hare been issued stating that the Commercial Standard for Special Screw Threads may be considered effective for new production as of July 1 . 1930.

This commercial standard covers limiting dimensions and tolerances for classes $1,2,3$, and 4 fits of the Anerican National 12-pitch thread scries as well as other screw threads of special dimensions. pitches. and lengths of engagements. The tables given comprise the most eswential dimensions as recommended by the National serew Thread Commission and are recommended primarily for shop use. 


\section{TESTING TYPEWRITER RIBBONS}

\section{Requirements of Federal Specification for Typewriter Ribbons to Insure Legibility}

By C. E. WAtERs, National Bureau of Standards

The popular notion is that almost any intensely colored liquid can be used as writing ink. What gives the color and how the liquid is prepared are given no thought. A typewriter ribbon is another thing which is taken for granted, yet a great deal of technical skill goes into the making of it.

This starts when the bale of cotton is opened. Near the very beginning of the Federal specification (No. 167a) is the requirement that the cotton shall be "thoroughly combed and free from waste. It shail be evenly woven and free from an excessive number of avoidable imperfections of manufacture." Evidently the fabric can not be made in a careless or haphazard way.

Further requirements concerning the fabric are its thickness and its thread count, or number of threads per linear inch in each direction. If a ribbon has a high thread count it follows that it can not be excessively thick. Suppose it has 150 threads per inch of warp and of filling. Each thread will be slightly less than $\frac{1}{150}$ inch in diameter because there are spaces between them. So the thickness where two threads cross one another would be less than $\frac{2}{150}$ inch, even if each did not slightly indent the other. The influence of these two factors will be made plain by a simple calculation. The specification limits the thickness to 0.0057 inch. If the threads were in close contact with those beside them, and did not indent one another, this thickness would correspond to a count of 350 in each direction, for $\frac{1}{350}$ equals $0.00286 \mathrm{inch}$, which is almost exactly half of 0.0057 .

Although thread count limits the thickness, the reverse is not true. Mosquito netting is thin, yet has a low thread count. The specification calls for a moderately high count so that the ribbons will have a comparatively smooth, fine-grained surface and will not be so thick as to give blurred impressions.

\section{Manufacture of ribbons.}

Most ribbons are cut from wide pieces of fabric and have their edges gummed to prevent fraying. They are believed to be preferable to ribbons which are woven of the desired width. The tension of the filling threads near the selvages is apt to make them lie less flat than cut-edge ribbons. However, for some computing and recording machines selvage ribbons are preferred because of their greater tensile strength.

The ink used on typewriter ribbons consists of an oily vehicle mixed with solid pigments which impart the color. The manufacturer shows his skill and experience in making the ink and in applying it to the ribbon evenly and in the required amount. The inking must be light, medium, or heavy, to suit different users. As previously stated, carbon is an exceedingly permanent pigment. It is also an excellent pigment for making the ink for typewriter ribbons. The blow of the type forces part of the carbon into the interstices between the paper fibers, where it should remain indefinitely, or as long as the paper lasts. Naturally, for the best results the ribbon should not have been used so long as the writing is gray instead of black.

Colored ribbons contain dyes, usually in the form of insoluble lakes, which are intimate mixtures of dye and inert mineral matter. Though it may take a great many years, the dye will finally fade, so only black record ribbons should be used for writing important documents that are to be kept for a long time. In addition to the usual pigments, copying ribbons contain soluble dye. When moistened in a letter press, enough of this dye to make a copy of the writing will dissolve.

\section{Testing ribbons.}

In testing ribbons, 25 short lines are written in rapid succession over exactly the same part of the ribbon, so as to find out how rapidly the ink will be exhausted. The first lines should not be too inky, nor the last unduly faint. The best ribbon is the one which shows the least decrease in blackness of writing from one line to the next. After the 25 lines have been written the ribbon is allowed to rest for an hour, after which one more line is written. If there is good "recovery," or flow of ink from the adjacent parts of the ribbon to replenish the exhauisted spot, this last line should be as black as the third line of the 25 .

In actual use, a ribbon is not put to so hard a test as this. It moves forward a little after each stroke of the type, and no part of it is written over more than once without being given time to recover. A ribbon is 12 yards long, and all but a few inches at each end is written on. The point exactly midway between the ends moves forward almost 6 yards and back the same distance before it is again struck by the type. It is easy to see how the point at the beginning of the ribbon, where the type first hits, will travel nearly 24 yards before it again comes into play. On the average, any given point on the ribbon travels almost 12 yards before coming under the type a second time.

A serious fault of some ribbons is that the ink fills the loops of a, e, and other letters, which causes an unsightly blur on the paper and gives a blotchy effect to the writing. A simple test for this fault is to write the letter e 800 times. With a good ribbon the last e will be as sharp as the first. A moderately bad ribbon will be detected before the end of the test. Sometimes, in an extremely bad case, ink will accumulate in the loop of the e, will be picked out by the ribbon, and will again accumulate. This may occur several times while the 800 e's are being written.

Sometimes when a ribbon is approaching the end of its useful life, a page of writing will show great unevenness in blackness, as if the ribbon were not uniformly inked. This effect is certainly not due to variations in the operator's touch. The ribbon is generally blamed for being unevenly inked. There is no practicable laboratory test for detecting this condition. 
Only by writing continuously for a great many hours or days, and using many sheets of paper, can the ribbon be brought to the state where evidence of uneven inking will be apparent. Attempts to uniformly remove enough of the ink to bring the ribbon nearly to the end of its life would have the tendency to dis- tribute the ink more evenly and would thus defeat the test.

(In a forthcoming issue of the Commracial STaxdARDS Monthur the author will present the third and last chapter of his article, which will deal with carbon paper.)

\section{STANDARDIZATION BRIEFS}

The success that has marked the simplification of paint and rarnish brushes and floor sweeps has prompted the American Brush Manufacturers" Association to request the services of the division of simplified practice of the National Bureau of Standards in developing a recommendation covering dutch, semidutch, and baby dutch kalsomine brushes. Multiplicity of sizes seems to run rampant in this line of brushes, and a reduction to those sizes and types which meet the largest demand of the consumers should result in very definite economies to the industry.

The report of the committee on standards for constant current transformers, which has been available in printed form since June, 1929, has been recommended for approval and publication as an American Institute of Electrical Engineers standard. The final standard will include certain revisions of the material contained in the report. These revisions are the result of suggestions received since the general circulation of the report.

The committee of the American Institute of Electrical Engineers on automatic stations has recommended the revision of standard No. 26, automatic stations. The revision consists in certain changes in functional numbers used to designate apparatus, and also changes in the table showing requirements for minimum protection of power apparatus.

A plan has been inaugurated for the standardization of all hydrants and fire-fighting equipment in the State of South Carolina, according to Sam B. King, insurance commissioner of that State. Although this work can not be expected to diminish the number of fires, it can be readily seen that, with the present day of good roads and fast motor-driven rehicles and standard equipment, the possibility of an uncontrollable conflagration will be next to impossible.

Reprints of American Petroleum Institute standardization bulletin No. 104, presenting Belt Fastener Report for 1929, by Glenn H. Bowlus, General Petroleum Corporation of California, have been mailed to members of the institute's division of production committee on standardization of oil-field belting. The reprint contains a summary of the work of the committee on this subject, with suggestions for improved practice.

A proposed American stanclard for rolled threads for screw shells of electric sockets and lamp bases has been developed by a committee of the American Society of Mechanical Engineers, working under the procedure of the American Standards Association.
This proposal is now being distributed to the industry for general criticism and comment.

A preliminary meeting of manufacturers was held in Utica, N. Y., May 26 , for the purpose of appointing a simplified practice committee and to study the combined report of the survey made in conjunction with the division of simplified practice and the Associated Knit Underwear Manufacturers of the U. S. A.

The sectional committee of the American Institute of Electrical Engineers on insulated wires and cables has prepared three new specifications as follows: Specifications for weatherproof (weather-resisting) wires and cables; specifications for heat-resisting wires and cables: and specifications for code rubber insulation for wire and cable for general purposes. These specifications can be obtained, for comment, from Francis J. White, care of the Okonit Co., 501 Fifth Arenue, New York, N. Y.

Manufacturers of wooden tubs for butter, lard, etc. have been circularized for comment on the possibility of developing a simplification program in this field

More than 40 manufacturers of hay presses are being circularized in order to ascertain whether or not they believe there is a need for simplification of varieties of this machine.

The report on air-circuit breakers, No. 20, has been recommended for approral and publication as ar American Institute of Electrical Engineers standard. The report has been arailable in printed form since June. 1928. The final standard will be identical with the printed report with the exception of the addition of fire definitions as follows: High-speed breaker, trip-free electrically and mechanically. interrupting rating. standard operating duty, interrupting performance.

Manufacturers of steel joists, through their association. the Steel Joist Institute, hare requested the division of simplified practice to call a general conference of all interests to consider for approval, a tentatire simplified practice recommendation which ther have drafted. This conference will probably be held in July of this year.

An extensive revision of the standards for transformers, induction regulators and reactors. No. 13, has been approred by the standards committee of the American Institute of Electrical Encrineers. The rerised standard will be arailable shortly as a new edition of No. 13. 


\title{
UNIFORMITY OF TRAFFIC LAWS URGED
}

\section{Third Annual Conference on Street and Highway Safety Recommends That All States Adopt the Uniform Vehicle Code and Model Ordinance}

\author{
By Col. A. B. BARBer, Direetor, National Conferenee on Street and Highway Safety
}

Standardization and uniformity of laws and ordinances and of traffic signs and markings provide the most direct approach to solution of the intricate problem of vehicular congestion and prevention of accidents in the view of the Thidd National Conference on Street and Highway Safety. Uniformity should extend also to driving practices and rules of the road.

The vehicular problem is essentially one for the States and cities to handle. While it is recognized that it calls for concerted action of governmental authorities of all States and cities, and of civic organizations and public bodies, the task does not come within the proper functions of the Federal Government. The Federal authorities have sought, however, to be of assistance to the States and cities in approaching the problem without encroaching upon authority that belongs to them.

\section{Congestion mainly in cities.}

Congestion in its most acute form is probably found in cities and towns with street systems that were designed many years ago to accommodate an entirely different class of traffic and type of vehicles from those in use at this time. Practical solution of the traffic problem in many of these towns and cities must ultimately be found in changes in the street systems to accommodate the new conditions that have arisen.

The program of the National Conference on Street and Highway Safety, which is advisory to the States and cities, is divided naturally into ways and means for immediate improvement, and into changes that contemplate permanent relief. The conference expressed the belief that adequate control of traffic at important street crossings, with enforcement of sound regulations, the proper marking of streets and highways, and standardized practices, will in the majority of cases afford immediate improvement. Permanent relief, however, will require a longer period of time. and involves the question of adequate finances, street and road rearrangement, and uniformity of State laws and municipal ordinances.

The conference said in its final report "effective and lasting remedies must correct the primary causes of congestion; they must put the available facilities to the best use; provide needed additional traffic capacity, and coordinate land utilization with traffic and transportation facilities.'

\section{Uniform vehicle code.}

The Uniform Vehicle Code of the conference, regulating traffic on public highways, has already been adopted in whole or in substantial part by approximately half of the States of the Union. The experience of the States and cities where it has been adopted indicates that it has proved distinctly successful in application. and, with few exceptions, has been found adequate for the purposes intended. The conference took emphatic stand on the position that the remain- ing States and municipalities should accept the uniform code and model ordinance.

It was pointed ont that political boundaries from the standpoint of traffic have been largely wiped out and the motor vehicle has created a universally recognized need for uniformity in traffic laws and regulations in all jurisdictions which participate in any considerable degree in vehicle movement between dififerent jurisdictions. Uniformity of laws is desirable to assure an effective and harmonious regulation throughout the country and to facilitate understanding by the motor driver of the requirements of any State or locality in which he may find himself.

\section{Code divided into four parts.}

The uniform code is divided into four acts, as follows: (1) Uniform motor vehicle registration act; (2) uniform motor vehicle antitheft act; (3) uniform notor vehicle operators' and chauffeur's license act; and (4) uniform act regulating traffic on highways. The model municipal traffic ordinance is supplementary to the Uniform Vehicle Code and is designed to meet the needs of municipalities for standardized regulations conforming to State laws. In addition, there is recommended a standard system of street traffic signs, signals, and markings, which hare been devised by a committee of the American Engineering Council after a thorough study of practices and tendencies. The conference stated as follows:

State laws should prescribe a uniform system of enforcement to be app'ied in part by State adm nistrative machinery and the State courts and in part by the local authorities. The necessary special traffic control and traffic patrol police should be provided and the regular police should cooperate in traffic enforcement. Provision sliould be made for prompt and thorough collection of evidence and investigation of accidents; for the proper preparation of traffic cases for trial ; for special traffic courts or special traffic sessions of general courts, and traffic violations bureaus with a schedu'e of penalties for disposing of minor infractions, so as to give the courts more time to deal adequately with more serious cases; uniform permanent records of all convictions of traffic $r$ olations and traffic accideuts, suspensions and rerocations of operator's licenses, and rcfusals to grant licenses; and the exchange of detailed information betreen jurisdictions as to suspensions and revocations of licenses and convictions for serious traffic offenses. The courts, the prosecut ing attorneys, and the police, through vigorous enforcement and even-handed treatment of offenders, should instill in the public respect for the traffic laws and regulations. Pubic opinion in support of enforcement should be organized through a representative citizens' committee in each locality, forming part of an organized effort of all elements in the community interested in street and highway accident reduction.

\section{Recommendations of conference.}

The conference also made recommendations as to standard road-building practices. In this respect the conference said that there should be: (1) Adequate roadway width for the traffic, with separate footways along highways with heary vehicular and perlestrian traffic, and adequate rights of way to provide for parking space, clear view at curves and intersections, and 
future roadway widenings; (2) space for parking off the traveled portion of rural highways, either continuously or at intervals not exceeding 300 feet; (3) reasonable grades of not more than 6 per cent where feasible, and curves of not less than 300 feet radius, on highways of primary importance, with widening and banking of curves; (4) avoidance of combinations of heavy grades and sharp curves; (5) cross sections of the pavement or roadway as flat as drainage conditions will permit; (6) guard railings of substantial type on the shoulder of embankments; ( 7 ) clear view of approaching vehicles for at least 500 feet on highways of primary importance, provided by necessary control of private advertising signs on the right of way or on private property near the highway, and by removing the trees, shrubs, and sloping banks on $\mathrm{Or}^{*}$ off the light of way, and cutting down sharp hill crests; (8) bridges at least 22 feet wide to enable two lines of traffic to pass without difficulty, and suitable provision for the safety of pedestrians on such bridges; (9) careful selection and wide marking of detours, with theil maintenance in safe condition, and the prompt removal of obsolete detour or temporary construction signs; (10) maintenance in good condition of pavements and roadway shoulders; (11) prompt removal of snow from streets and highways of heavy traffic; and (12) proper illumination of city streets and of highways wherever financially practicable.

Adequate and ample protection of highway intersections is deemed by the Third National Conference on Street and Highway Safety to be one of the most important phases of assuring the safety of the road and reducing and forestalling accidents and vehicle mis- haps. Not only should the physical hazards be removed, but special protective measures, such as signs and markings, should be installed. These signs and markings, the conference urged, should be uniform in every State and on every highway. The hazard at highway intersections is such as to require the same safety measures and precautions as are taken in respect to railway grade crossings.

The conference stated that the special protective measures and safeguards at highway intersections in the way of standard fixed signs and markings should be as follows:

Advance warning signs in the form of standard "cross road" or "side road" signs at approaches to highway intel'sections where the crossings would not otherwise be readily recognized, or where there is a hazard that is not otherwise obvious; also, center line markings on roadways of heary traffic, and lane markings on wide roadways. At points nearel the intersection 20-mile speed signs where the view is obstructed or other special hazards exist and the highway is not protected against crossing traffic by stop signs; and stop signs at the entrances to through highways; also, where these signs can not be seen sufficiently in advance, the placement of standard "slow" signs, and with parement markings, if necessary, to supplement them.

Short directional lines on the pavement with arrow to indicate direction, $01^{\circ}$ suitable traffic markers or buttons to direct the movement of traffic within the intersection. Where the traffic is dense on both of the $h$ ghways at an intersection, the conference believes that unless grade separation is economically practicable there should be a stop-and-go control of traffic by automatic lights or by traffic officers. Where the traffic is dense on one road and light on the other, the conference believes that traffic-actuated control signals afford a practical means of avoiding excessive interruption of the travel on the main thoroughfare, or undue delay of traffic on the smaller road.

\section{RED CEDAR CLOSET LINING}

\section{Conference Approves Proposed Standard}

On May 23, at Chattanooga, Tenn., a general conference was called by the division of trade standards of those interested in the manufacture, sale, and use of red cedar closet lining.

This meeting considered and approved for recommendation to the entire industry standard grading rules for aromatic red cedar closet lining. This commercial standard is a minimum specification for clothescloset lining made only from genuine aromatic red cedar (Juniperus virginiana) and covers width, thickness, minimum length, matching, heartwood requirements, and permissible defects.

It is the desire of the manufacturers to set a high quality standard for this product. Accorcling to the recommended standard the red heartwood which produces the characteristic cedar aroma must constitute $75 \mathrm{or}^{\circ}$ more per cent of the face of each piece.

In ardition to the standard specifications there are given some of the manufacturer's' recommendations for the most efficient construction of cedar closets and precautions necessary in the storing of clothes and other articles in cedar closets and other cedar storage receptacles.

These recommended standards are being circulated to manufacturers, distributors, and consumers of cedar lining for their formal approval and copies may be had by addressing the Division of Trade Standards, National Bureau of Standards, Washington, D. C.

\section{MAXIMUM SPANS FOR JOISTS AND RAFTERS}

New Handbook of National Lumber Manufacturers Association Deals with Problems of Interest to Construction Industry

A new handbook of Maximum Spans for Joists and Rafter's has been published by the National Lumber. Manufacturers Association, for the guidance of architects, engineers, contractors, and carpenters. Span tables are given for joists of various sizes and spacing, with different live loads, and for plastered as well as unplastered ceilings.

There are also tables fol maximum spans of ceiling joists and attic floor joists, rafters, and roof joists. I complementary table deals with the area of cross section, weight per linear foot, moment of inertia, and section modulus of American standard dressed sizes of nominal timber sizes, from 2 by 4 up to 24 by 30 inches.

A foreword explains the use of the tables and shoms how their application to species and garde of lumber may be determined by the local building code or by reference to the forthcoming Working Stresses for Structural Timber, another publication of the National Lumber Manufacturers Issociation in its construction information series. 


\title{
VALUE OF DISTRIBUTION CENSUS TO MANUFACTURERS
}

\author{
Survey Data Will Serve as Basis for Developing Standard Marketing Practices
}

Manufacturers probably will derive nearly as much benefit from the census of distribution as will accrue to either wholesale or retail dealers, according to the Bureau of the Census of the Department of Commerce. For years alert and progressive manufacturers have been searching constantly for comprehensive and reliable data regarding markets and the country's distributive system in order to adapt their productive processes to the changed and changing conditions in wholesale and retail trade.

In response to the demand of the business world generally, Congress authorized the census of distribution to be taken as a part of the fifteenth decennial census. As a result of this nation-wide survey of the vast distributive field, statistical tabulations will be compiled which will form a great storehouse of information of direct value to manufacturers. Figures regarding the size of each establishment in the Nation engaged in distribution, the activities of chain stores, the prevalence of cash as against credit operations, and other data needed by manufacturers in laying out sales quotas and sales campaigns will be made a vailable.

All retail stores, little or big, no matter where located, in downtown districts, outlying sections, towns, villages, and country crossroads; also wholesalers, jobbers, and commission merchants are being canvassed in the census. Others included are construction contractors doing $\$ 25,000$ worth of business; hotels having 25 rooms or more; automobile repair shops, restaurants, butchers and abattoirs, country buyers of farm products, cooperative buying and selling organizations, brokers, supply houses, and equipment dealers.

\section{Scope of inquiries.}

The inquiries of the distribution questionnaires are designed to reveal information concerning the geographical distribution of the various types of retail and wholesale outlets, the kind of merchandise handled and by what stores, in the various sections of the country. A question also will be asked of all manufacturers, which will reveal the extent to which manufacturers are engaged in wholesale and retail merchandising activities, and will show the extent to which their products are sold through the assistance of agents. When the census is completed accurate and complete information should be available showing the manner in which the manufacturers of each of the 340 different kinds of industries in the country are selling their products.

The statistics will show to what extent manufacturers are performing the functions of both the wholesaler and retailer through direct selling to the consumer, or through their affiliated, owned, or controlled retail stores. They will also show the extent to which the manufacturers are selling direct to retail stores, other than their own, through their affiliated, owned, or controlled branch wholesale houses; likewise the extent to which manufacturers of different sizes in different localities and in different industries are utilizing manufacturers' agents.

Such data will indicate the changes being wrought in the manufacturing and merchandising mechanism of the country. All this information will be available geographically as well as industrially and by size of establishment.

\section{NEW STANDARD OF LIGHT FIRST SUGGESTED BY WAIDNER AND BURGESS}

During the past tivo years the National Bureau of Standards has perfected a light source which is suitable for use as a primary standard of light.

Up to the present time no satisfactory standard has been available. In this country the unit of light (the candle) has been maintained by a group of 45 carbonfilament electric lamps, to which have been assigned definite ratings when burned under specified conditions. To keep the size of the unit of candlepower unchanged with such electric-lamp standards it was necessary that no changes take place in the lamps themselves, a requirement which can not be met indefinitely by any electric lamp or group of lamps.

The new light source consists of a hollow inclosure of fused thoria immersed in a bath of pure freezing platinum. It is reproducible in that it can be set up anew at any time and does not depend upon the unchanging character of any particular pieces of material. It depends only upon the constancy of a natural phenomenon, namely, the fact that pure platinum will always freeze at the same temperature. The light emitted each time the source has been set up anew has been found to be the same, as compared with the bureau's carbon electric lamp standards, within 1 part in 1,000. This is about the limit of accuracy attainable in photometry.

The old electric lamp standards were irreplaceable and their loss or a serious change in their properties, such as must eventually occur, would in the past, have been nothing less than a catastrophe. If, however, such a loss occurred now, the bureau could replace these lamps without the assistance of outside laboratories by rating a new set of lamps in terms of the light emitted by the platinum standard. The relation of this light to the present unit of candlepower has been accurately established as one candle for each 1,700 square millimeters of opening.

It happens, fortunately, that the color of the light emitted by the new standard is practically identical with that emitted by the old standard. It is hoped that before very long the new light source will be recognized generally and adopted as an international standard. 


\title{
CURRENT ACTIVITIES OF THE AMERICAN STANDARDS ASSOCIATION
}

\author{
Yearbook for Association Announced; New Projects Reviewed
}

The American Standards Yearbook, a review of the National standardization activities of the American Standards Association during the past year, has just been published by the association. The following are among the high spots of the year's activities as noted in the yearbook:

The underwriting by industry of nearly $\$ 500,000$ for the promotion of national standardization during the next three years. The affiliation of the American Standards Association with the national standardizing bodies of 20 other nations through the International Standards Association. This body, which has its headquarters at Zurich, Switzerland, will promote international cooperation in standardization work; important progress in the standardization of products directly affecting the ultimate consumer, such as textiles and household mechanical devices; increased recognition of the value of national industrial standards in the field of foreign trade; the completion of an agreement between the American Standards Association and the National Bureau of Standards providing for a maximum degree of cooperation between the Government and private bodies in the promotion of industrial standardization.

The economic importance of standardization is pointed out in a foreword to the yearbook by George B. Cortelyou, president of the Consolidated Gas Co. of New York, who says:

Standardization is of prime importance at the present time to practically every American industry as a means of promoting industrial stabilization and of minimizing unemployment. It permits the continuous production of products and parts, during periods of slackened buying, in anticipating of future demand. For the same reason, it makes for steady employment of labor. It broadens markets nationally, and even internationally. As a principal means of introducing improvements in design and economies in production and distribution, it furthers the sound development of industries and helps to open potential markets. On these grounds alone it merits sympathetic study on the part of every business executive. In all this, the American Standards Association, which occupies movement, is performing an indispensable function-making the key position in the national industrial standardization for stability, growth, and service.

At the time the yearbook went to press the association had approved 166 national industrial standards and 171 other standardization projects were under way. Among these are both standards and projects affecting practically every American industry. The new standards approved during the past year include important mechanical standards, such as tool holder shanks and tool post openings. In the electrical field, in addition to the standard for outlet boxes, there is a new standard of regulations for electric wiring and apparatus in relation to fire hazard, the code for protection against lightning, the first national standard for radio, fixing the dimensions governing fit of 4-pin vacuum tube bases, and the arrangement of terminals. The railroad industry is represented by a new standard for materials for use in the manufacture of special track work. Of interest to almost all engineers is the new standard for symbols for hydraulics, aeronautics, for electrical quantities, and for telephone and telegraph use.

The new projects initiated during 1929 include such subjects as annular ball bearing, method of laboratory sampling and analyses of coal and coke, standardization of Diesel fuel oils, specifications for coal-mine cars and for mine timbering, locomotives for coal mines, graphical symbols used in radio communication, and general methods of testing woven textile fabrics.

\section{Approves abrasive wheel safety code.}

Following the unanimous approval by the American Standards Association technical committee on the abrasive wheel safety code and by the Grinding Wheel Manufacturers of the United States and Canada, and the International Association of Industrial Accident Boards and Commissions, sponsors for the committee, the revision of the abrasive wheel safety code has been approved as an American standard by the association. The purpose of the code is to provide the rules and specifications necessary to insure safety in the use of abrasive wheels operating at peripheral speeds exceeding 2,000 feet per minute.

One of the most important changes in the revised code is that making the use of cast-steel protection hoods permissible. The code contains sections on types of protection devices, handling and storages, general machine requirements, protection hoods, work rests, protection for cup cylinder and sectional ring hoods, flanges, mounting, speed, and operating rules. It has been the policy of the grinding-wheel manufacturers of the United States to design their machines in accordance with the provisions of the original code. It is understood that this policy will be continued in connection with the revised code.

\section{Standards for symbols.}

A table of symbols for photometry and illumination has been submitted to letter ballot of the association for approval as an American standard. The proposed standard was prepared by a subcommittee of the general A. S. A. techñical committee on scientific and engineering symbols and abbreviations which is under the sponsorship of the American Association for the Advancement of Science, the American Institute of Electrical Engineer's, the American Society of Civil Engineer's, the American Society of Mechanical Engineers, and the Society for the Promotion of Engineering Education.

A standard on this subject was originally adopted in 1925. Revision was undertaken at the time of the organization of the general committee on scientific and engineering symbols and abbreviations in 1926. One of the last changes made in the code was the addition of equations defining the meanings of the symbols.

One of the problems considered by the committee was the use of the symbols " I" and " $\mathrm{E}$ " for illumina- 
tion and luminous intensity, respectively. It was noted that these symbols are identical with symbols previously recommended for certain electrical quantities. 'The subcommittee reported that "while the general principle of avoiding the use of the same symbols for two different quantities is a good one * * * nevertheless, these letters are so well established in this connection, having international recognition as well as national, that it has appeared undesirable to change the accepted practice." The standard provides, however, for alternative symbols where confusion may result.

The proposed standard for navigational and topographical symbols has also been submitted for the approval of the American Standards Association and sent to letter ballot. This standard has also been approved by the technical committee on scientific and engineering symbols and abbreviations and by the sponsors.

\section{PLATINUM PLATING FOR ANALYTICAL WEIGHTS}

\section{Even Platinum-Plated Weights May Not Be Constant}

For many years platinum plating was generally considered a doubtful value for weights. The character of the plating done by different firms differed widely, the platinum coating was likely to be very porous, and the weights tended to gain excessive anounts.

Within the past few years there appears to have been considerable improvement in the general character of platinum plating. In particular, sets of 1piece weights have shown very satisfactory behavior on boiling in distilled water, and on short-time tests of constancy under good atmospheric conditions.

These improvements induced the National Bureau of Standards about two years ago to try platinum plating on some old sets of ordinary analytical weights that were in need of repair. These weights were of the usual screw-knob type, and some trouble was experienced because of failure to thoroughly wash out the cavity under the knob. Such trouble, however, may be experienced from any kiud of electroplating on weights of this type. Thirteen sets of these weights, repaired at various times, have been retested during the past three months. All but three sets had been in use under fairly good conditions, since the weighing rooms where they were used are separate from the laboratories. The three unused sets had been kept in the stock room for about six months.

\section{Changes recorded.}

The unused sets showed no significant changes, the maximum apparent change being $0.03 \mathrm{mg}$. There is some doubt as to whether many sets are likely to show this degree of constancy even under these conditions.

Weights of the sets which had been regularly in use showed a marked tendency to gain. There were no significant losses even in sets which had been used to: such an extent that losses normally would be expected through wear. About 30 per cent of the weights gained nearly or more than $0.1 \mathrm{mg}$. The two largest changes were those of two 100-g weights, one of which gained $0.4 \mathrm{mg}$ and the other $0.8 \mathrm{mg}$. These results do not prove that platinum plating causes a greater tendency to change than would be caused by plating with other metals, but they do show conclusively that platinum plating can not be relied on to produce constant weights. Any plated weights, no matter what plating is used, must be carefully checked for constancy.

Porosity of the brass, resulting in surface spotting of many of these weights, may account for some of the tendency to change. Therefore, there is danger in electroplating old weights, especially old lacquered weights, because they may be made of porous metal. Moreover, some of the weights tarnished without any definite evidence of porosity while some weights gained serious amounts without any evident tarnishing or spotting. Among the latter was one set that had been plated at the National Bureau of Standards.

In repairing old sets the advantages of platinum plating may sometimes outweigh the danger of inconstancy, especially where the weights can be recalibrated often enough to insure the accuracy of the values used. 'The experience with these weights shows, however, that danger of some inconstancy must be included in the consideration of advantages and disadvantages.

\section{PLUG AND RING GAGE BLANKS}

\section{Industry Adopts Standard Effective July 1}

Under date of June 2, 1930, the National Bureau of Standards announced the success of the Recommended Commercial Standard for Plain and Thread Plug and Ring Gage Blanks; and that, sufficient written acceptances having been received, the commercial standard became effective July 1, 1930, for new production.

The standard includes details of construction for plain cylindrical plug qage blanks, thréad plug gage blanks, plain ring gage blanks, thread ring gage blanks of all sizes above 0.059 to and including $41 / 2$ inches diameter and the official monogram used to identify such gages. The recommendation applies to gage blanks only and does not attempt to set up dimensions or tolerances for finished gages.

The standard was developed by the American Gage Design Committee as a means for simplification of gaging practice through the adoption of standard designs for gage blanks and component parts. While the committee was given full support and recognition by the American Standards Association, the War and Navy Departments, and the National Screw Thread Commission, the majority of the work was contributed by the industry itself, many of the country's largest industrial units in widely diversified fields being represented by active membership on the committee.

The committee's efforts to make available in every instance the best possible design of gage blank was materially furthered by the generous action of the gage manufacturers on the committee, all of whom offered without reservation to dedicate to public use their proprietary patent rights on any gage construction the utilization of which might be desired by the committee. 


\section{SCIENTIFIC, TECHNICAL, AND COMMERCIAL PERIODICAL PUBLICATIONS ISSUED BY THE NATIONAL BUREAU OF STANDARDS}

\section{BUREAU OF STANDARDS \\ JOURNAL OF RESEARCH}

The new Journal describes the bureau's research results in science and technology. The union of science and its applications in one journal shortens the lag between discovery and application.

All engaged in industry and commerce should have available for current use and permanent reference, the Bureau of Standards Journal of Research.

Early in its first year the Journal developed a list of paid subscribers double the anticipated maximum.

This Journal is full of interest to executives and technicians controlling industries and commercial enterprises. It enables them better to promote efficiency by determining the scientific measu red controls of process through experimental and theoretical research.

Issued monthly

Subscription price, $\$ 2.75$ per year

\section{COMMERCIAL STANDARDS MONTHLY}

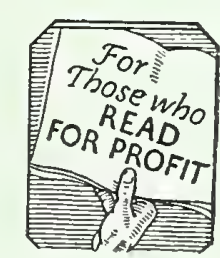

\section{TECHNICAL NEWS BULLETIN}

The Bureau of Standards periodical with a WAR RECORD! Started during the dark days of 1917 to keep the Army and Navy and other branches of the Government informed of progress in scientific war research at the bureau. Upon urgent request this publication was continued and expanded to serve the Government, science, and industry.

The TECHNICAL NEWS BULLETIN will keep you informed of current progress in the scientific and technical work of the bureau's laboratories, and gives each month a list of the publications of the bureau. A complete cross index is published with the December issue.

You can not afford to be without the TECHNICAL NEWS BULLETIN. Every article is short and to the point. The busiest executive can afford the time to read it.

Issued monthly

Subscription price, 25 cents per year

\section{STANDARDS YEARBOOK FOR 1930}

This new governmental periodical is a review of progress in commercial simplification and standardization. It is the only journal of its kind. It covers the national movement initiated by President Hoover for the reduction of needless sizes and varieties of products and the promotion of voluntary commercial standardization by industry.

The Secretary of Commerce in the first issue of this new journal said: "Certain standards, such as those used for weights and measures, $* * *$ have been fixed by legislative enactment. Mandatory standards of this character, however, are few in number when compared with the large and steadily growing volume of standards developed by industry and commerce and voluntarily maintained. ${ }^{*} *{ }^{*}$ The activities of the Commercial Standardization Group of the Bureau of Standards are concerned with standards adopted by voluntary agreement."

Subscription price, $\$ 1$ per year
The new Standards Yearbook for 1930 is the fourth annual issue of a publication devoted to the great and growing field of standardization in its broad aspects. It gives a summary of progress.

Standardization is a world-wide movement. It covers all industries. It is part of the application of scientific methods to industry. Its achievements are of interest and concern to business men and manufacturers as well as to engineers. To the technician it is full of example of methods and results of suggestive and stimulating value. To business men it discloses trends which deeply concern their interest.

"Standardization is becoming an aspect of all wellordered activity rather than an incidental activity supplemental to others."

\section{NOW READY Price, $75 \mathrm{c}$. ORDER AT ONCE}

To obtain regularly the above-described monthly periodicals send your order, with remittance, addressed: Superintendent of Documents, Government Printing Office, Washington, D. C. Foreign prices (countries other than the United States and its possessions, Canada, Mexico, Newfoundland, Cuba, and Republic of Panama) are: Journal, $\$ 3.75$; Bulletin, $\$ 0.40$; Monthly, $\$ 1.25$; Yearbook, $\$ 0.90$ 
“* * * this department $* * *$ is devoted solely to aiding and fostering the development of higher standards of living and comfort of our people $* * *$ its ideals are clear: That by cooperation and not by compulsion it should seek to assist in maintaining and giving the impulse of progress to commerce and industry in a nation whose successful economic life underlies advancement in every other field. - President Hoover, at the laying of the corner stone of the new building of the U. S. Department of Commerce, June 10, 1929.

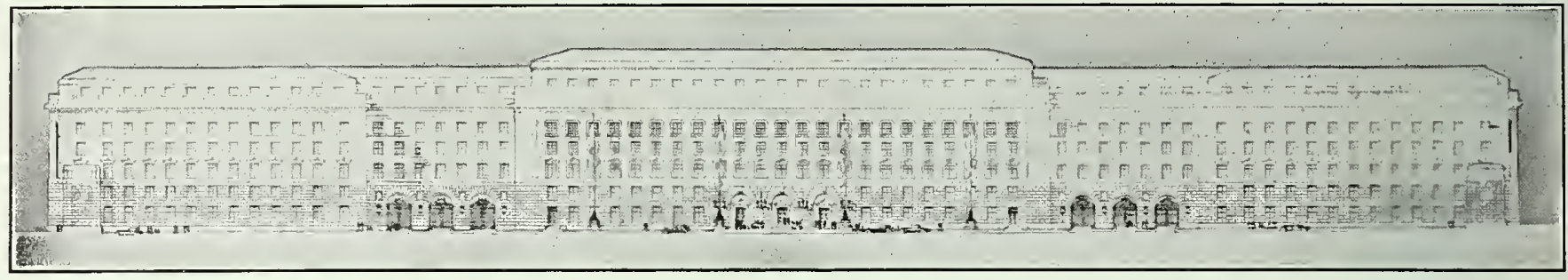

\section{THE UNITED STATES DEPARTMENT OF COMMERCE}

\section{R. P. LAMONT, Secretary of Commerce}

aERonaUtics BRanCH, Clarence M. Yodng, Assistant Secretary of Commerce for Aeronautics.

Establishment of civil airways and maintenance of aids to air navigation: inspection and registration of aircraft and licensing of pilots; enforcement of air traffic rules; investigation of accidents; encouragement of municipal air ports; fostering of air commerce; scientific research in aeronautics; and dissemination of information relating to commercial aeronautics. (Some of these functions are performed by special divisions of the Lighthouse Service, the Bureau of Standards, and the Coast and Geodetic Survey.)

BUREAU OF THE CENSUS, William M. Stedart, Director.

Taking censuses of population, mines and quarries, water transportation, and religious bodies every 10 years; censuses of agriculture and electrical public utilities every 5 years; and a census of manufactures every 2 years. Compilation of statistics of wealth, public debt and taxation, including financial statistics of local governments, every 10 years; annual compilation of financial statistics of State and municipal governments

Compilation of statistics of marriage, divorce, births, deaths, and penal and other institutions annually, and of death rates in cities and automobile accidents weekly.

Compilation quarterly or monthly of statistics on cotton, wool, leather, and other industries; annually of forest products and publication monthly of Survey of Current Business.

BUREAU OF FOREIGN AND DOMESTIC COMMERCE, William L. CoOper, Director.

The collection of timely information concerning world market conditions and openings for American products in foreign countries, through commercial attachés, trade commissioners, and consular officers, and its distribution through weekly Commerce Reports, bulletins, confidential circulars, the news and trade press, and district and cooperative offices in 65 cities. The maintenance of commodity, technical, and regional divisions to afford special service to American exporters and manufacturers.

The compilation and distribution of lists of possible buyers and agents for American products in all parts of the world and publication of weekly lists of specific sales opportunities abroad.

The publicity of statistics on imports and exports.

The study of the processes of domestic trade and commerce.

BUREAU OF STANDARDS, George K. Bdrgess, Director.

Custody, development, and construction of standards of measurement, quality, performance, or practice; comparison of standards used by scientific or other institutions; determination of physical constants and properties of materials; researches and tests on materials and processes; and publication of scientific and technical bulletins reporting results of researches and fundamental technical data.

Collection and dissemination of information concerning building codes and the planning and construction of houses.

Establishment of simplified commercial practices through cooperation with business organizations in order to reduce the wastes resulting from excessive variety in commodities.

BUREAU OF MINES, Scott TURner, Director.

Technical investigations in the mining, preparation, and utilization of minerals, including the study of mine hazards and safety methods and of improved methods in the production and use of minerals.

Testing of Government fuels and management of the Government Fuel Yard at Washington.

Research on helium and operation of plants producing it.

\section{BUREAU OF MINES-Continued.}

Studies in the economics and marketing of minerals and collection of statistics on mineral resources and mine accidents.

The dissemination of results of technical and economic researches in bulletins, technical papers, mineral resources series, miners' circulars, and miscellaneous publications.

BUREAU OF Fisheries, Henry O'Mallex, Commissioner

The propagation and distribution of food fish and shellfish, in order to prevent the depletion of the fisheries; investigations to promote conservation of fishery resources; the development of commercial fisheries and agriculture; study of fishery methods, improvements in merchandising, and collection of fishery statistics; administration of Alaska fisheries and fur seals; and the protection of sponges off the coast of Florida.

BUREaU OF Lighthouses, George R. Pdtnam, Commissioner.

Maintenance of lighthouses and other aids to water navigation. Establishment and maintenance of aids to navigation along civil airways. Publication of Light Lists, Buoy Lists, and Notices to Mariners.

\section{COAST AND GEODETIC SURVEY, R. S. PATTON, Director}

Survey of the coasts of the United States and publication of charts for the navigation of the adjacent waters, including Alaska, the Philippine Islands, Hawaii, Porto Rico, the Virgin Islands, and the Canal Zone; interior control surveys; magnetic surveys; tide and current observations; and seismological investigations. Publication of results through charts, coast pilots, tide tables, current tables, and special publications.

BUREAU OF NAVIGATION, Arthur J. TyRer, Commissioner.

Superintendence of commercial marıne and merchant seamen.

Supervision of registering, enrolling, licensing, numbering, etc., of vessels under the United States flag, and the annual publication of a list of such vessels.

Enforcement of the navigation and steamboat inspection laws, including imposition of fees, fines, tonnage taxes, etc.

STEAMBOAT INSPECTION SERVICE, DickERSON N. Hoover, Supervising Inspector General.

The inspection of merchant vessels, including boilers, hulls, and life-saving equipment, licensing of officers of vessels, certification of able seamen and lifeboat men, and the investigation of violations of steamboat inspection laws.

UNITED STATES PATENT OFFICE, Thomas E. Robertson, Commissioner.

The granting of patents and the registration of trade-marks, prints, and labels after technical examination and judicial proceedings.

Maintenance of library with public search room, containing copies of foreign and United States patents and trade-marks. Recording bills of sale, assignments, etc., relating to patents and trade-marks. Furnishing copies of records pertaining to patents. Publication of the weekly Official Gazette, showing the patents and trade-marks issued.

RADIO DIVISION, W. D. Terreli, Chief.

Inspection of radio stations on ships; inspection of radio stations on shore, including broadcasting stations; licensing radio operators; assigning station call letters; enforcing the terms of the International Radiotelegraphic Convention; and examining and settling international radio accounts. 